Original Research

\title{
The Relationship Between Working Posture and Anthropometric Compatibility with Workstations: A Case Study Among Sewing Operators
}

\author{
Fakhradin Ghasemi $^{1}$, Maedeh Hasini², Mojtaba Ahmadi ${ }^{3}$, Mostafa Rahminai-Iranshahi ${ }^{2 *}$ \\ 1. Assistant Professor, Ergonomics Department and Occupational Health and Safety Research Center, School of Public \\ Health, Hamadan University of Medical Sciences, Hamadan, Iran \\ 2. MSc Student, Occupational Health Department and Students Research Center, School of Public Health, Hamadan \\ University of Medical Sciences, Hamadan, Iran \\ 3. BSc Student, Occupational Health Department and Students Research Center, School of Public Health, Hamadan \\ University of Medical Sciences, Hamadan, Iran
}

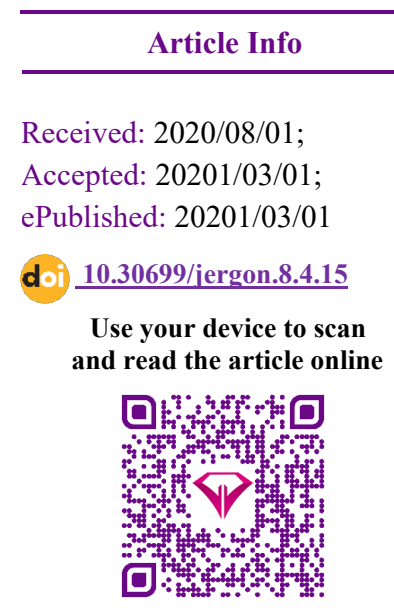

Corresponding Author

Mostafa Rahminai

Iranshahi

MSc Student, Occupational Health

Department and Students

Research Center, School of Public

Health, Hamadan University of

Medical Sciences, Hamadan, Iran

Email:

mrahmiani@gmail.com

\section{ABSTRACT}

Background and Objectives: Designing workstations in accordance with anthropometric characteristics of employees can prevent awkward working postures and reduce the risk of such disorders. The present study aimed at investigating the anthropometric compatibility of workstations in a sewing company and its relationship with working postures.

Methods: This cross-sectional study was conducted in a sewing company located in Hamadan province, Iran. Working postures were assessed in standing and sitting workstations using REBA and NERPA techniques, respectively. Anthropometric dimensions were measured in accordance with ISO 7250 and anthropometric compatibility with workstation was investigated. Mann-Whitney test was used for assessing the relationship between anthropometric compatibility and working posture.

Results: A total of 205 employees with a mean age of 31.29 years participated in this study. Working postures were mostly in an unacceptable condition and the need for ergonomic intervention was evident. In sitting workstation, there was no significant relationship between working postures and anthropometric compatibility in terms of seat depth, seat width, and backrest height. In contrast, anthropometric compatibility with seat height and desk height were significantly associated with working posture $(P<0.05)$. In standing workstations, a significant relationship was observed between anthropometric compatibility and desk height $(P<0.05)$.

Conclusion: Anthropometric incompatibility with workstation generally deteriorated the working postures. However, anthropometric compatibility with seat height and desk height were the ones with a significant relationship with working posture. Therefore, for redesigning workstations the seat height and desk height should be considered first.

Keywords: Workstation design, Musculoskeletal disorders, Sewing industries

\footnotetext{
Copyright (C) 2021, This is an original open-access article distributed under the terms of the Creative Commons Attribution-noncommercial 4.0 International License which permits copy and redistribute of the material just in noncommercial usages with proper citation.
}

\section{How to Cite This Article:}

Ghasemi F, Hasini M, Ahmadi M, Rahmiani-IranShahi M. The relationship between working posture and anthropometric compatibility with workstations: a case study among sewing operators. Iran J Ergon. 2020; 8 (4):1530 


\section{Extended Abstract}

\section{Introduction}

Designing workstations in accordance with anthropometric characteristics of employees can prevent awkward working postures and reduce the risk of such disorders. The present study aimed at investigating the anthropometric compatibility of workstations in a sewing company and its relationship with working postures.

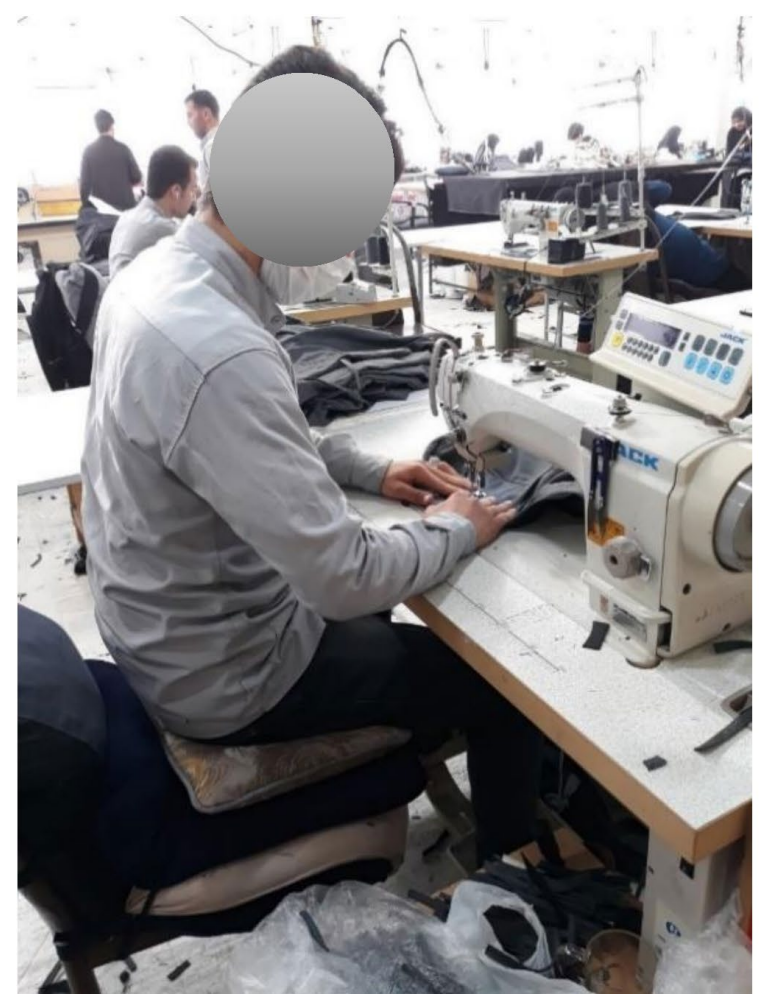

Figure 1. Posture of the operator in a standing and sitting position

\section{Results}

A total of 205 employees with a mean age of 31.29 years participated in this study. Working postures were mostly in an unacceptable condition and the need for ergonomic intervention was evident. In sitting workstation, there was no significant relationship between working postures and anthropometric compatibility in terms of seat

\section{Methods}

This cross-sectional study was conducted in a sewing company located in Hamadan province, Iran. Working postures were assessed in standing and sitting workstations using REBA and NERPA techniques, respectively. Anthropometric dimensions were measured in accordance with ISO 7250 and anthropometric compatibility with workstation was investigated. Mann-Whitney test was used for assessing the relationship between anthropometric compatibility and working posture.

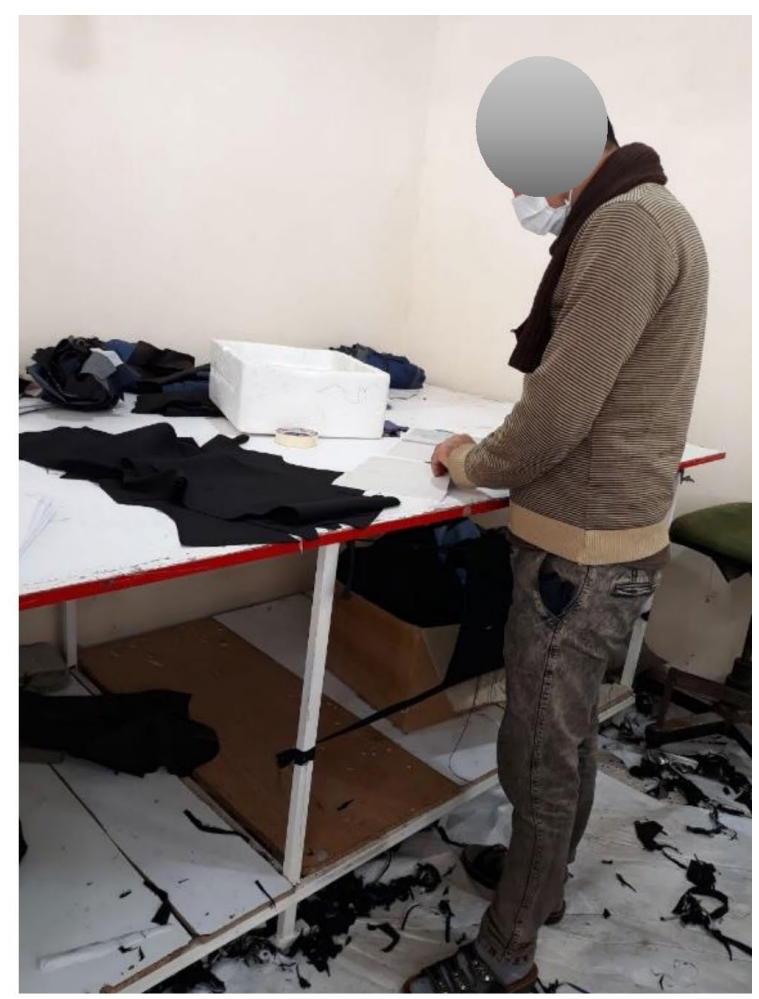

depth, seat width, and backrest height. In contrast, anthropometric compatibility with seat height and desk height were significantly associated with working posture $(P<0.05)$. In standing workstations, a significant relationship was observed between anthropometric compatibility and desk height $(P<0.05)$. 
Fakhradin Ghasemi et al.,

Table 1. Relationships for determining whether or not there is a correlation between the anthropometric dimensions of individuals and the dimensions of the workstation

\begin{tabular}{|c|c|}
\hline \multicolumn{2}{|r|}{ Sitting workstations $[10,11]$} \\
\hline Seat height adjustment range & $(P+2) \cos (30) \leq \mathbf{S H} \leq(P+2) \cos (5)$ \\
\hline Seat width adjustment range & $1.1 \mathrm{H} \leq \mathbf{S W} \leq 1.3 \mathrm{H}$ \\
\hline Seat depth adjustment range & $0.80 \mathrm{~PB} \leq \mathrm{SD} \leq 0.99 \mathrm{~PB}$ \\
\hline $\begin{array}{l}\text { Rear seat height adjustment } \\
\text { range }\end{array}$ & $0.6 S \leq B \leq 0.8 S$ \\
\hline $\begin{array}{l}\text { Sitting table height } \\
\text { adjustment range }\end{array}$ & $E+[(P+2) \cos (30)] \leq \mathbf{S i T H} \leq[(P+2) \cos (5)+(0.8517 E)+(0.1483 S)$ \\
\hline \multicolumn{2}{|l|}{ Standing workstation [14] } \\
\hline $\begin{array}{l}\text { Desk height adjustment } \\
\text { range }\end{array}$ & $\mathrm{EH}-15 \leq \mathbf{S t T H} \leq \mathrm{EH}-10$ \\
\hline $\begin{array}{l}\text { In these relationships, } \mathrm{P} \text { is the hip } \\
\text { hip width (buttock), } \mathrm{PB} \text { is the dep } \\
\text { elbow height in the standing posi }\end{array}$ & $\begin{array}{l}\text { eight in the sitting position, } \mathrm{S} \text { is the shoulder height in the sitting position, } \mathrm{H} \text { is the } \\
\text { of the hip buttocks, } \mathrm{E} \text { is the height of the elbow in the sitting position and } \mathrm{EH} \text { is the } \\
\mathrm{n} \text {. Also, } \mathrm{SH} \text { is the seat height, } \mathrm{BH} \text { is the rear seat height, } \mathrm{SW} \text { is the seat seat width, }\end{array}$ \\
\hline
\end{tabular}
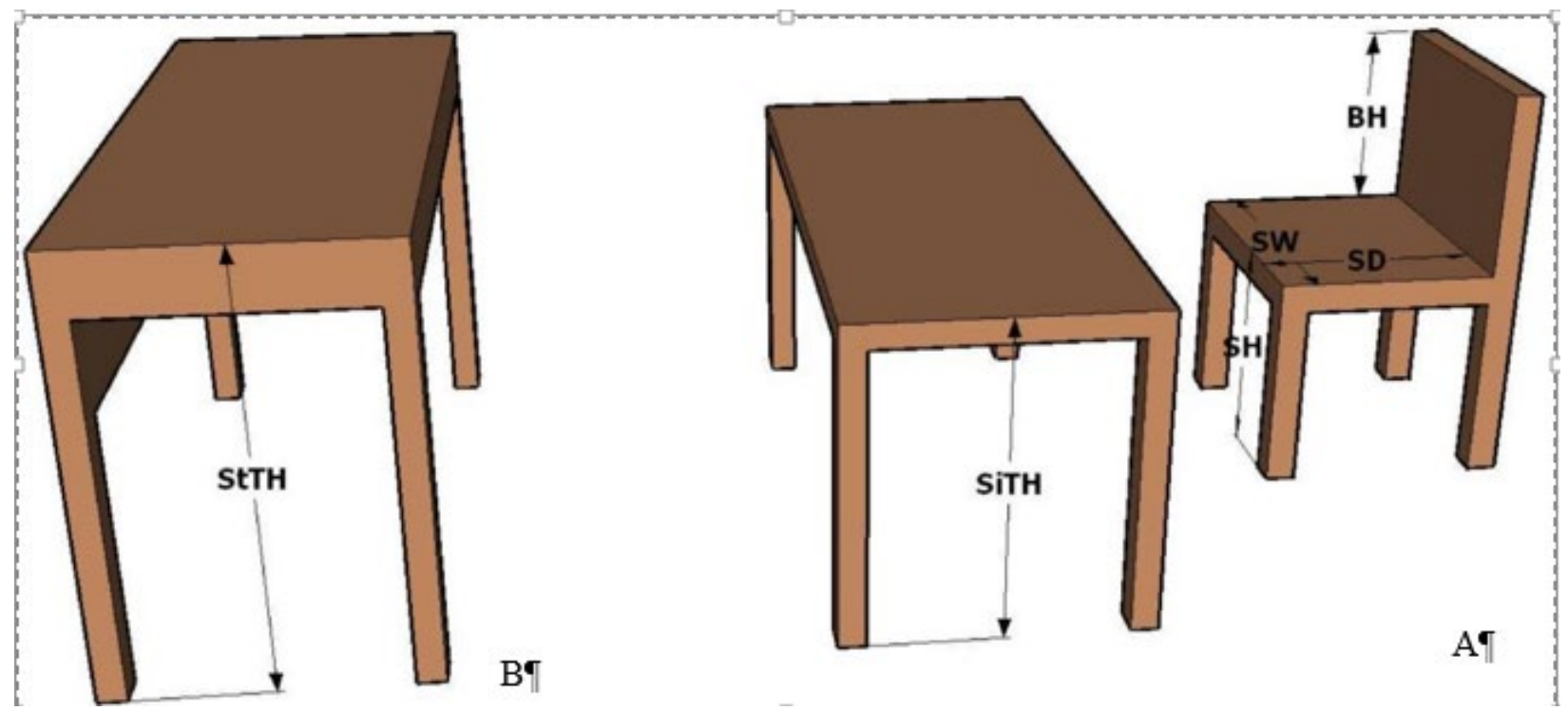

Figure 2. Anthropometric dimensions and workstations investigated in the present study. A) Sitting workstation; B) Standing workstation

Table 2. Anthropometric dimensions of individuals in sitting workstations (105 people)

\begin{tabular}{|lllll|}
\multicolumn{1}{c}{$\begin{array}{c}\text { Anthropometric } \\
\text { dimensions }\end{array}$} & M & SD & Percentile 5 & Percentile 95 \\
\hline Rider height & 44.51 & 3.50 & 41.21 & 49.00 \\
\hline Depth of capillary & 44.30 & 6.25 & 36.22 & 53.01 \\
\hline The depth of the buttocks & 52.03 & 4.51 & 35.05 & 61.70 \\
\hline $\begin{array}{l}\text { Elbow height in sitting } \\
\text { position }\end{array}$ & 22.40 & 3.56 & 17.81 & 28.00 \\
\hline Button width & 34.72 & 6.46 & 25.25 & 44.23 \\
\hline Space of thighs & 15.50 & 3.97 & 10.30 & 24.40 \\
\hline $\begin{array}{l}\text { Shoulder height in sitting } \\
\text { position }\end{array}$ & 56.58 & 7.22 & 48.00 & 64.70 \\
\hline Sitting height & 82.65 & 8.17 & 62.20 & 93.00 \\
\hline
\end{tabular}




\begin{tabular}{|c|c|c|c|c|}
\hline Anthropometric dimensions & $\mathbf{M}$ & SD & Percentile 5 & Percentile 95 \\
\hline Coarse height & 44.27 & 6.74 & 37.00 & 51.95 \\
\hline $\begin{array}{l}\text { The height of the knuckle } \\
\text { protrusion }\end{array}$ & 64.35 & 8.02 & 56.00 & 72.95 \\
\hline Elbow height & 107.05 & 12.00 & 97.05 & 120.00 \\
\hline Shoulder height & 140.00 & 14.86 & 128.05 & 12.95 \\
\hline $\begin{array}{l}\text { Access limit in standing } \\
\text { position }\end{array}$ & 71.69 & 8.52 & 63.00 & 80.00 \\
\hline
\end{tabular}

Table 4. Relationship between workstation compliance and posture final score in seated workstations (Mann-Whitney test)

\begin{tabular}{|c|c|c|c|c|}
\hline $\begin{array}{l}\text { Dimensions of } \\
\text { workstation }\end{array}$ & Compliance status & $\mathbf{N}(\%)$ & $\begin{array}{c}\text { Posture Score } \\
\text { (NERPA) } \\
\text { Mean (SD) }\end{array}$ & P-value \\
\hline \multirow{2}{*}{$\begin{array}{c}\text { The size of the back } \\
\text { of the chair }\end{array}$} & Not a match & $20(19 \%)$ & $4.75( \pm 0.91)$ & \multirow{2}{*}{0.99} \\
\hline & Not a match & $85(81 \%)$ & $4.69( \pm 1.08)$ & \\
\hline \multirow[t]{2}{*}{ Seat height } & Not a match & $32(30.5 \%)$ & $4.37( \pm 1.23)$ & \multirow{2}{*}{0.01} \\
\hline & Not a match & $73(69.5 \%)$ & $4.84( \pm 0.92)$ & \\
\hline \multirow{2}{*}{ Seat width } & Not a match & $41(39 \%)$ & $4.58( \pm 1.18)$ & \multirow{2}{*}{0.57} \\
\hline & Not a match & $64(61 \%)$ & $4.78( \pm 0.95)$ & \\
\hline \multirow[t]{2}{*}{ Seat depth } & Not a match & $77(73.3 \%)$ & $4.64( \pm 1.01)$ & \multirow{2}{*}{0.23} \\
\hline & Not a match & $28(26.7 \%)$ & $4.85( \pm 1.14)$ & \\
\hline \multirow{2}{*}{ Desk height } & Not a match & $17(16.2 \%)$ & $4.23( \pm 1.20)$ & \multirow{2}{*}{0.05} \\
\hline & Not a match & $88(83.8 \%)$ & $4.79( \pm 0.99)$ & \\
\hline \multirow{2}{*}{ Gender } & Male & $61(58 \%)$ & $4.68( \pm 0.97)$ & \multirow{2}{*}{0.86} \\
\hline & Female & $44(41 \%)$ & $4.72( \pm 1.14)$ & \\
\hline \multirow{4}{*}{ BMI } & Lightweight & $6(5.7 \%)$ & $5.16( \pm 0.75)$ & \multirow{4}{*}{0.70} \\
\hline & Normal weight & $49(46.7 \%)$ & $4.69( \pm 1.08)$ & \\
\hline & Overweight & $36(34.3 \%)$ & $4.72( \pm 0.97)$ & \\
\hline & Fat & $14(13.3 \%)$ & $4.50( \pm 1.22)$ & \\
\hline \multirow{4}{*}{ Age } & Less than 20 years & $9(8.6 \%)$ & $4.33( \pm 1.00)$ & \multirow{4}{*}{0.38} \\
\hline & 20 to 29 years & $44(41.9 \%)$ & $4.84( \pm 1.09)$ & \\
\hline & 30 to 39 years & $33(31.4 \%)$ & $4.69( \pm 0.98)$ & \\
\hline & Older than 40 years & $19(18.1 \%)$ & $4.57( \pm 1.07)$ & \\
\hline
\end{tabular}

Table 5. Relationship between workstation compliance and final posture score in standing workstations (Mann-Whitney test)

\begin{tabular}{|c|c|c|c|c|}
\hline $\begin{array}{l}\text { Dimensions of } \\
\text { workstation }\end{array}$ & Compliance status & $\mathbf{N}(\%)$ & $\begin{array}{c}\text { Posture Score (REBA) } \\
\text { Mean (SD) }\end{array}$ & P-value \\
\hline \multirow{2}{*}{ Desk height } & Not a match & $19(19 \%)$ & $4.36( \pm 1.64)$ & \multirow{2}{*}{0.01} \\
\hline & Not a match & $81(81 \%)$ & $5.44( \pm 1.85)$ & \\
\hline \multirow{2}{*}{ Gender } & Male & $59(59 \%)$ & $5.32( \pm 1.63)$ & \multirow{2}{*}{0.57} \\
\hline & Female & $41(41 \%)$ & $5.12( \pm 2.14)$ & \\
\hline \multirow{2}{*}{ BMI } & Lightweight & $6(6 \%)$ & $5.33( \pm 2.25)$ & \multirow{2}{*}{0.66} \\
\hline & Normal weight & $47(47 \%)$ & $5.25( \pm 1.96)$ & \\
\hline
\end{tabular}




\begin{tabular}{|c|c|c|c|c|}
\hline $\begin{array}{l}\text { Dimensions of } \\
\text { workstation }\end{array}$ & Compliance status & $\mathbf{N}(\%)$ & $\begin{array}{c}\text { Posture Score (REBA) } \\
\text { Mean (SD) }\end{array}$ & P-value \\
\hline & Overweight & $34(34 \%)$ & $5.23( \pm 1.87)$ & \\
\hline & Fat & $13(13 \%)$ & $5.15( \pm 1.34)$ & \\
\hline \multirow{4}{*}{ Age } & Less than 20 years & $9(9 \%)$ & $5.33( \pm 2.17)$ & \multirow{4}{*}{0.78} \\
\hline & 20 to 29 years & $41(41 \%)$ & $5.17( \pm 2.18)$ & \\
\hline & 30 to 39 years & $31(31 \%)$ & $5.45( \pm 1.56)$ & \\
\hline & Older than 40 years & $19(19 \%)$ & $5.00( \pm 1.37)$ & \\
\hline
\end{tabular}
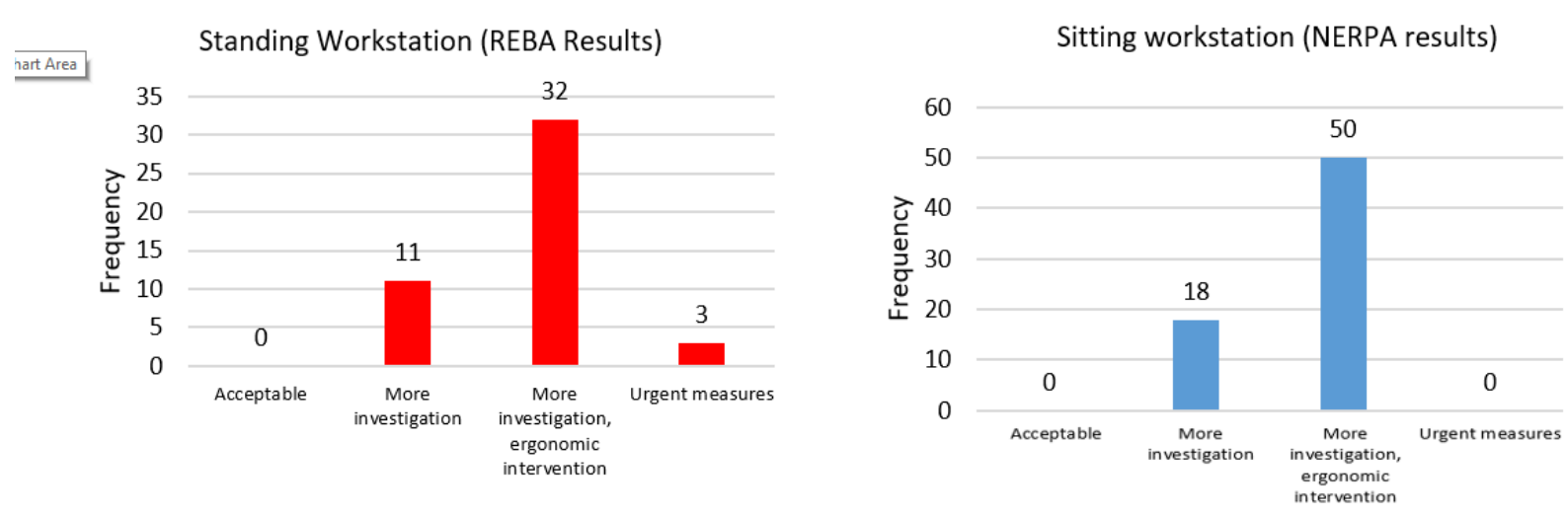

Figure 3. Ergonomic status of standing and sitting workstations (in NERPA method, scores 1 and 2 correspond to zero action level, scores 3 and 4 correspond to action level one, scores 5 and 6 correspond to action level two and more scores correspond to level 2 In the REBA method, points 1 correspond to action level zero, points 2 and 3 correspond to action level one, points 4 to 7 correspond to action level two, and higher scores correspond to action level three.

\section{Discussion}

In seated workstations, anthropometric correlation with chair height and desk correlation had a significant relationship with postural scoring. Also, in standing workstations, a significant relationship was observed between anthropometric correlation with desk height and postural work score. In addition, anthropometric incompatibility with workstations in all dimensions led to an increase in the average postural work score.

The results of postural evaluation by NERPA and RULA methods showed that the working conditions of individuals, whether in standing or sitting workstations, are generally not favorable; as the level of action required is two or more. These results are consistent with the findings of Nagaraj et al. [18] and Dianat et al. [6].

In this study, none of the postures examined had zero action level (score one and two in NERPA method and score one in REBA method). In this respect, the results of the present study are similar to the results of Ztürk and Esin study [4].

In addition, the results of the present study indicated that there is a significant relationship between anthropometric compliance with the workstation in terms of chair height and desk height. The results of this study are consistent with the results of Tondre et al. (2019) [20].

\section{Conclusion}

Anthropometric incompatibility with workstation generally deteriorated the working postures. However, anthropometric compatibility with seat height and desk height were the ones with a significant relationship with working posture. Therefore, for redesigning workstations the seat height and desk height should be considered first.

\section{Acknowledgement}

The authors of the article thank the esteemed Vice Chancellor for Research and Technology of 
Hamadan University of Medical Sciences for their financial support (Project number: 9811299100).

This study was reviewed and approved by the Research Ethics Committee of Hamadan University of Medical Sciences (Ethics Code: IR.UMSHA.REC.1398.969). In addition, participation in this study was completely voluntary and all individuals read and signed the informed consent form before entering the study.

\section{Conflict of Interest}

The authors declared no conflict of interest. 
رابطُٔ بين بوسجر كارى و تناسب آنترويومتريكى در ايستخاههاى كار: مطالعه موردى در جند صنعت بافندكى

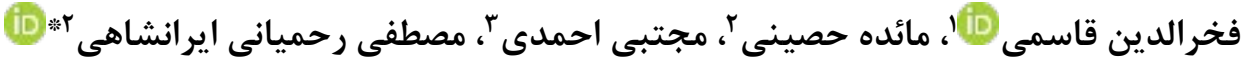

ا. . استاديار، كروه اركونومى و مركز تحقيقات بهداشت و ايمنى شغلى، دانشكدة بهداشت، دانشكاه علوم يزشكى همدان، همدان، ايران

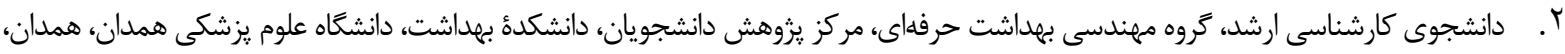

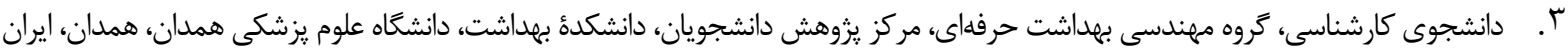

\begin{tabular}{|c|c|}
\hline خلاصه & اطلاعات مقاله اله \\
\hline زمينه و هدف: طراحى ايستًاههاى كارى متناسب با ابعاد آنترويومتريك از يوسجرهاى كارى نامطلوب & 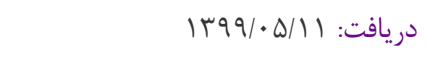 \\
\hline مىتواند بيشكيرى كند و خطر اختلالات اسكلتىعضلانى را كاهش دهد. هدف مطالعة حاضر بررسى تطابق & 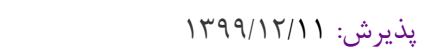 \\
\hline آنترويومتريك ايستًاههاى كارى و ارتباط آن با امتياز يوسجر كارى افراد شاغل در يكى از صنايع بافندَى & انتشار آنلاين: || \\
\hline بود. & نويسندة مسئول: \\
\hline 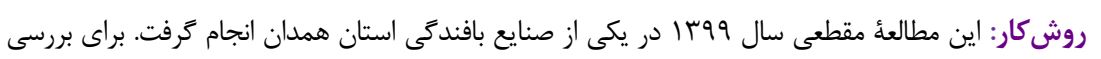 & مصطفى رحميانى ايرانشاهى \\
\hline يوسجر ايستًاههاى كارى نشسته و ايستاده روشهاى REBA NERPA بهكار رفت. ابعاد آنترويومتريك افراد & دانشجوى كارشناسى ارشد، كَروه \\
\hline براساس استاندارد ISO اندازهكيرى و تطابق آنترويومتريك افراد با ايستكاههاى كارى آنان ارزيابى شد. 7250. & مهيندسي بمداشت حرفهاي، مركز \\
\hline براى بررسى رابطة بين تطابق آنترويومتريكى و يوسجر افراد آزمون آمارى مَنويتنى استفاده شد. & ئزوهش دانشجويان، دانشكدة بهداشت، \\
\hline 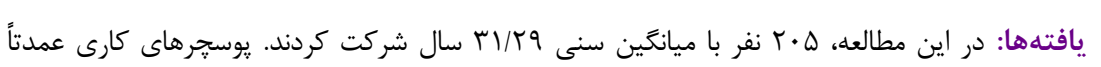 & دانشخاه علوم يزشكى همدان، همدان، \\
\hline وضعيت نامطلوب داشتند و نيازمند مداخلات اركَونوميكى بودند. در ايستكاهكارى نشسته، رابطؤ معنى دارى & \\
\hline بين تطابق آنترويومتريكى با عمق نشيمنتاه صندلى، عرض نشيمنكاه صندلى، ارتفاع يشتى صندلى و امتياز & 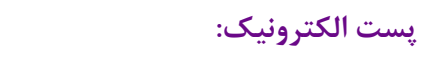 \\
\hline يوسجر كارى مشاهده نشد؛ ولى تطابقنداشتن آنترويومتريكى با ارتفاع صندلى و ارتفاع ميز كار رابطة & mrahmiani@gmail.com \\
\hline معنى دارى با يوسجر كارى افراد داشت (ه. •/PP). افزونبراين در ايستًاههاى كارى ايستاده، رابطة معنى دارى & u \\
\hline بين تطابق آنترويومتريكى با ارتفاع ميز كار و امتياز يوسجر مشاهده شد (ه / (P>P). & \\
\hline نتيجه كَيرى: تطابقنداشتن آنترويومتريك با ايستكاهكارى عموماً يوسجر كارى را نامطلوب مىكند. & 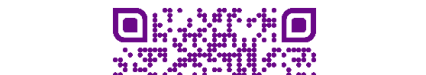 \\
\hline باوجوداين، تطابق آنترويومتريك با ارتفاع صندلى و ارتفاع ميز كار، تنها عوامل تأثيركذار بر امتياز يوسجر كارى & 8 \\
\hline بود؛ ازاينرو، براى بازطراحى ايستًاههاى كارى توجه ويزه به اين عوامل بيشنهاد مىشود. & $7+3$ \\
\hline كليدوازهها: طراحى ايستَاه كار، اختلالات اسكلتىضلانى، صنعت بافندىى & \\
\hline
\end{tabular}

مقدمه

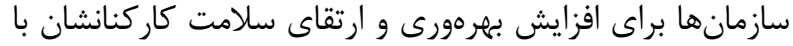

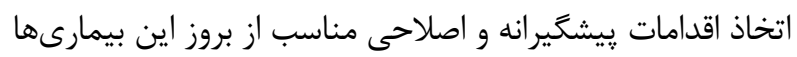

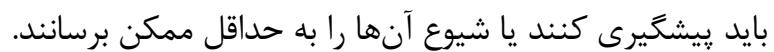

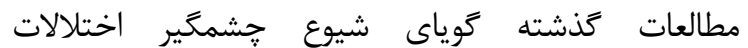

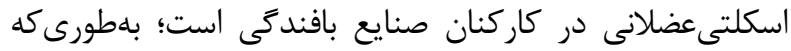
اكثر شاغلان از اين مسئله بهشدت شكايت مى كنند. در مطالعأ

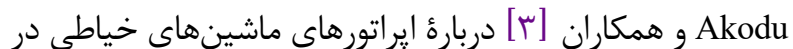

اختلالات اسكلتىعضلانى مشكلى مهم در صنعتها و

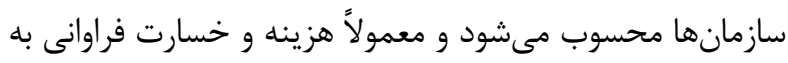

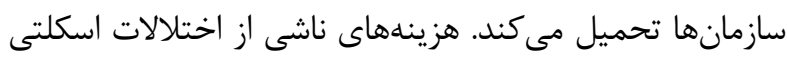
را مىتوان به دو دسته مستقيم و غيرمستقيم تقسيم كرد. هزينههاى مستقيم هزينههاى غرامت و درمان و هزينهان غيرمستقيم كاهش بهرهورى و كاهش كيفيت محصول توليدشده و افزايش غيبتهاى كار را شامل مىشود [ ا و r r]. بنابراين، 
هنكَت ميز و صندلى با ارتفاع تنظيميذير، مديران صنايع علاقهُ

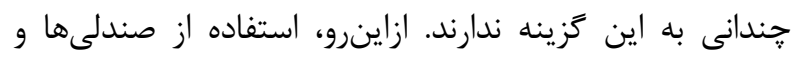

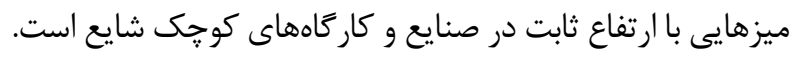

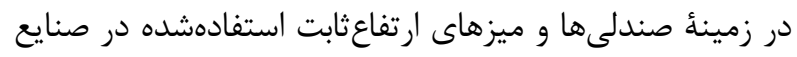

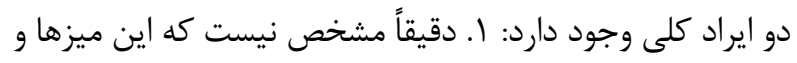

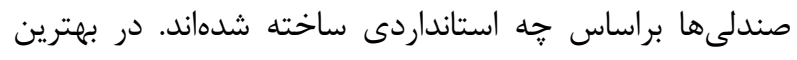

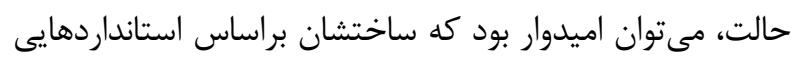

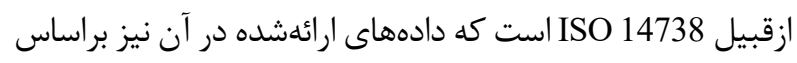

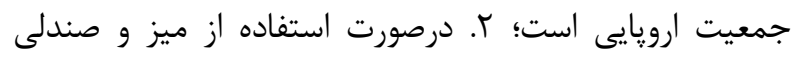

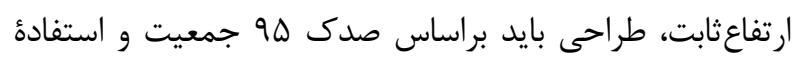

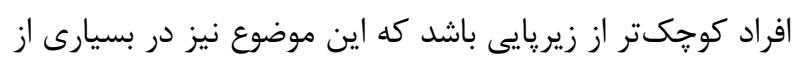

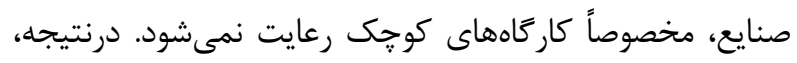

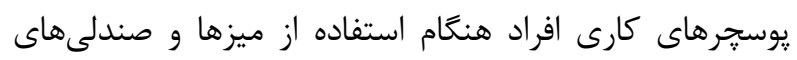

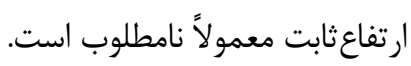

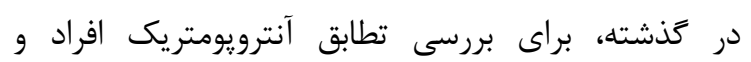

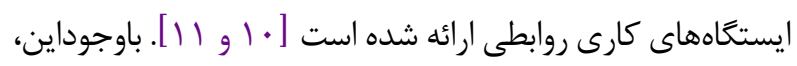

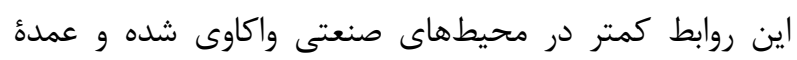

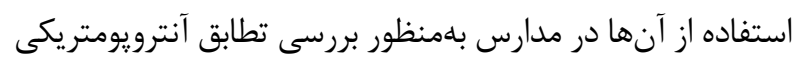

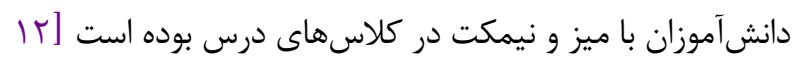

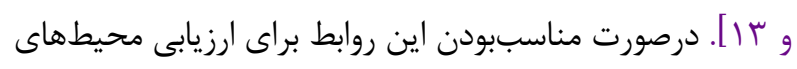

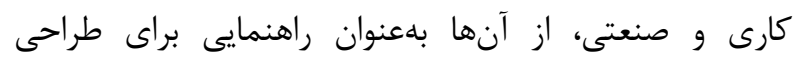

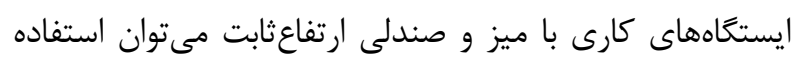

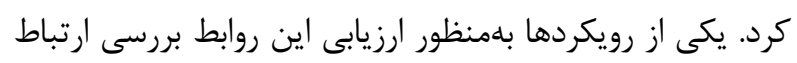

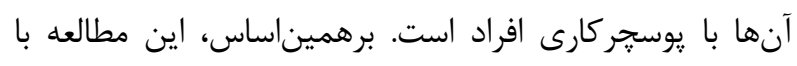

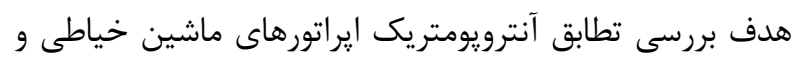

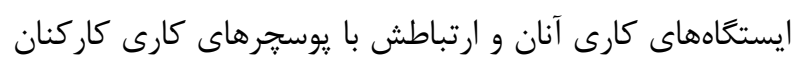

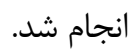

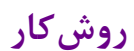

اين مطالعهُ توصيفى تحليلىمقطعى سال 99 با در يكى از

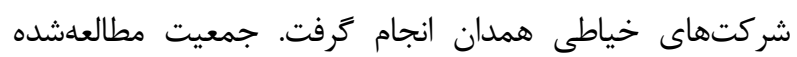

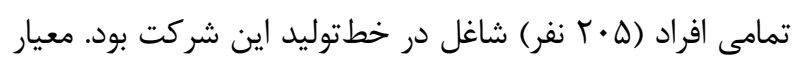

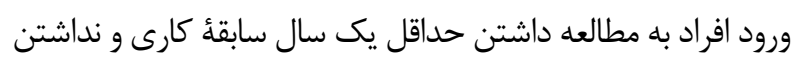
مشكل روحىجسمى در نظر كرفته شد. اين مطالعه در كميتئ اخلاق در يزوهش دانشعاه علوم يزشكى همدان بررسى و و با كد IR.UMSHA.REC.1398.969 تصويب شد. ييش از شروع كار، از

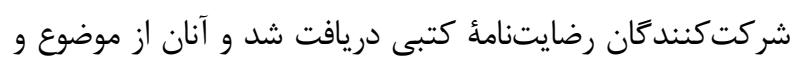
روش اجراى مطالعه مطلع شدند. مشاركت در تحقيق بار مالى براى داى داني
نيجريه، شيوع علائم اختلالات اسكلتى عضلانى دوازدمهاهه

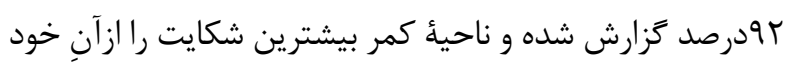

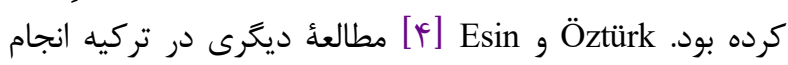

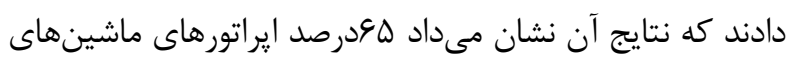

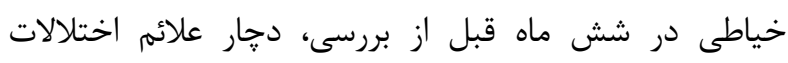

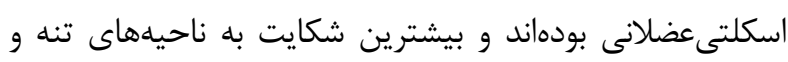

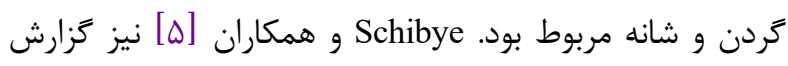

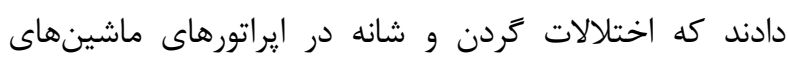

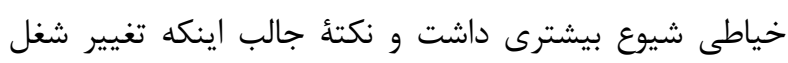

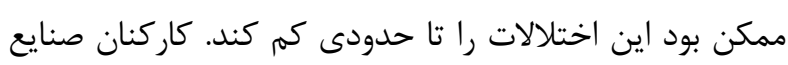

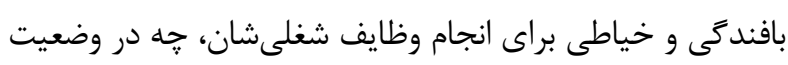

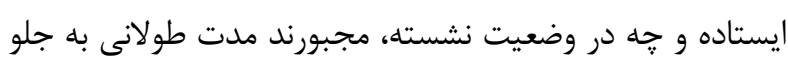

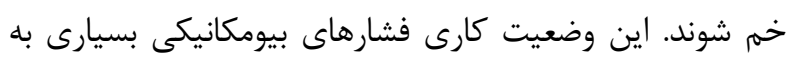

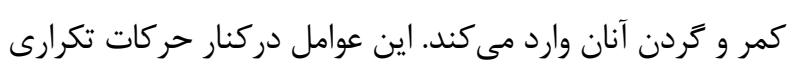

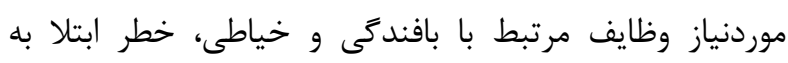

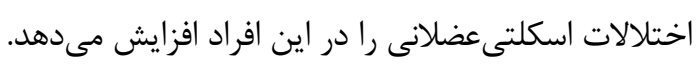

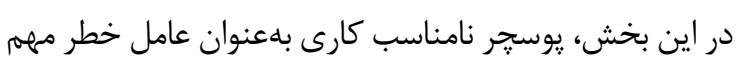

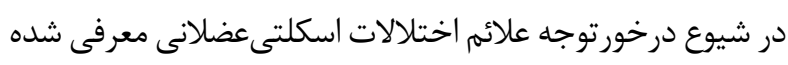

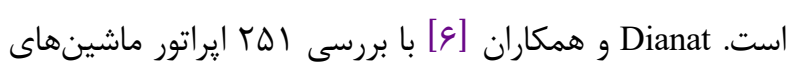

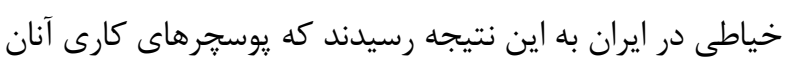

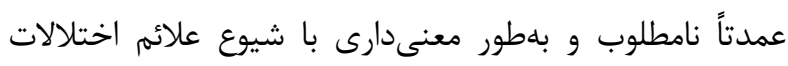

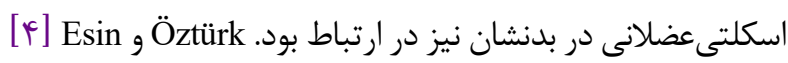

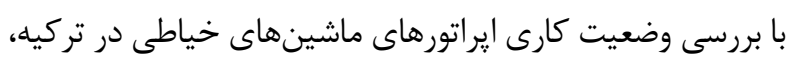

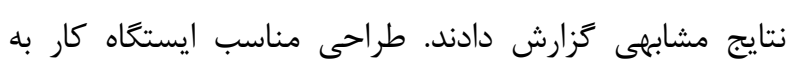

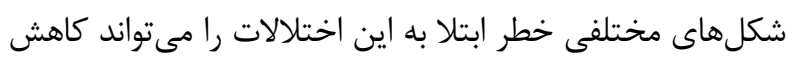

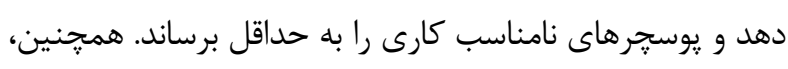

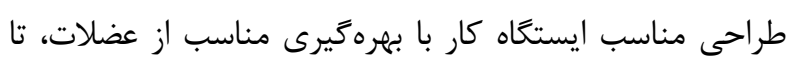

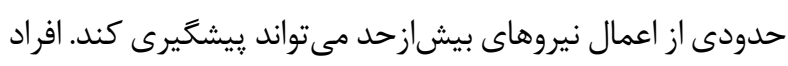

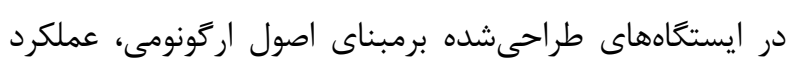

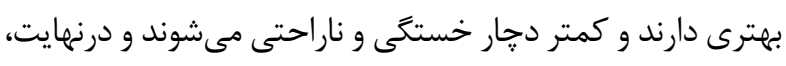

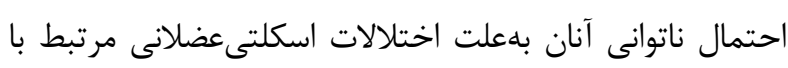

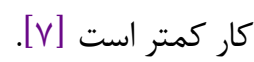

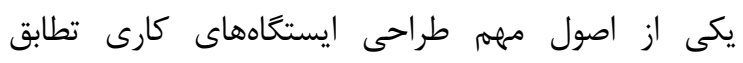

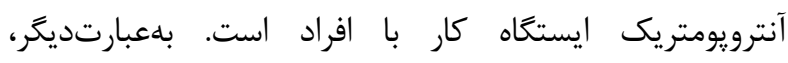

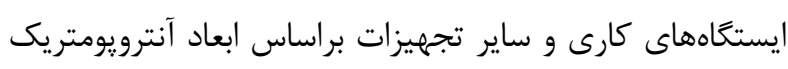

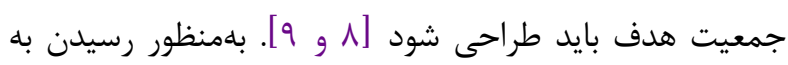

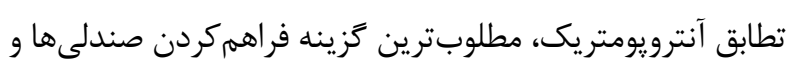

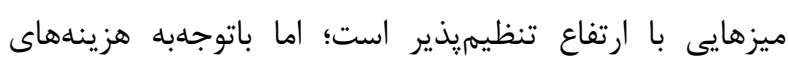


افراد در ايستخاههاى كارى نشسته و ايستاده وظايف شغلىشان را انجام مىدادند. ايستخاههاى كارى ايستاده براى انجام وظايفى لهى

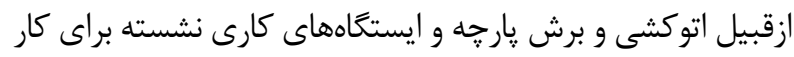
با ماشينهاى خياطى استفاده مىشدند (شكل لـ ().

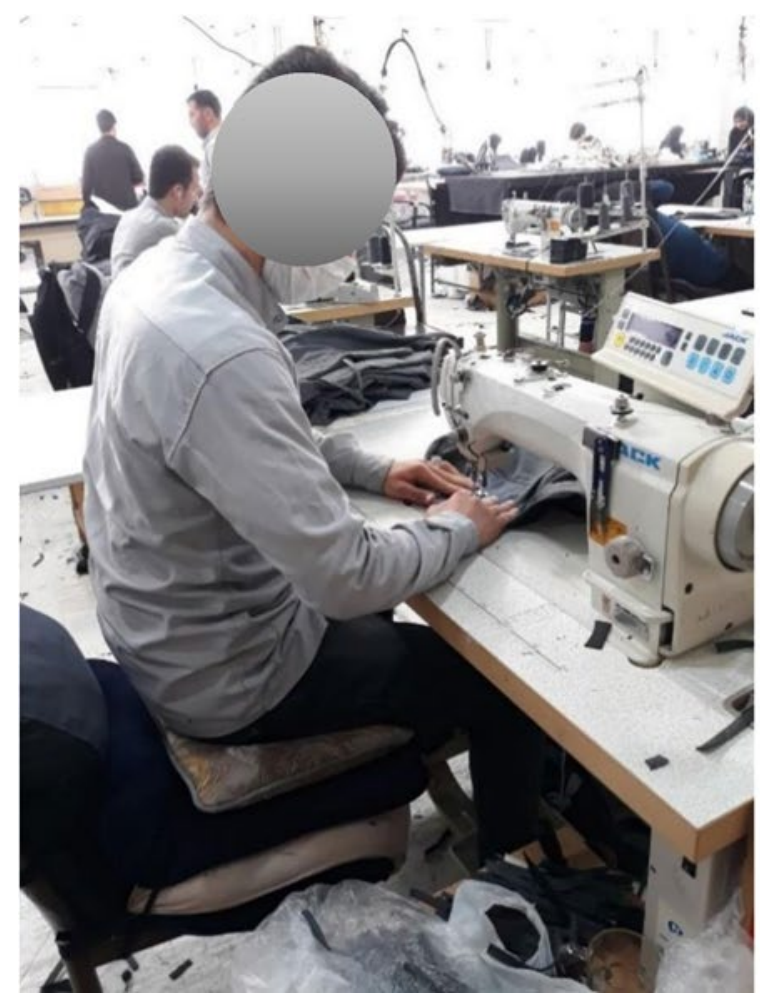

شركت كنندكان نداشت و آنان در هر زمان آزاد بودند در مطالعه شركت يا آن را ترك كنند. اطلاعات شركت كنند يرسشنامه اطلاعات جمعيتشناختى يروهشگرساخته گردآورى شد. در اين يرسشنامه، عواملى همجٍون سن، جنس، تأهل، سابقه كار، شاخص توده بدن، رضايت شغلى، ساعت كارى روزانه و سطح تحصيلات افراد در نظر گرفته شده بود.

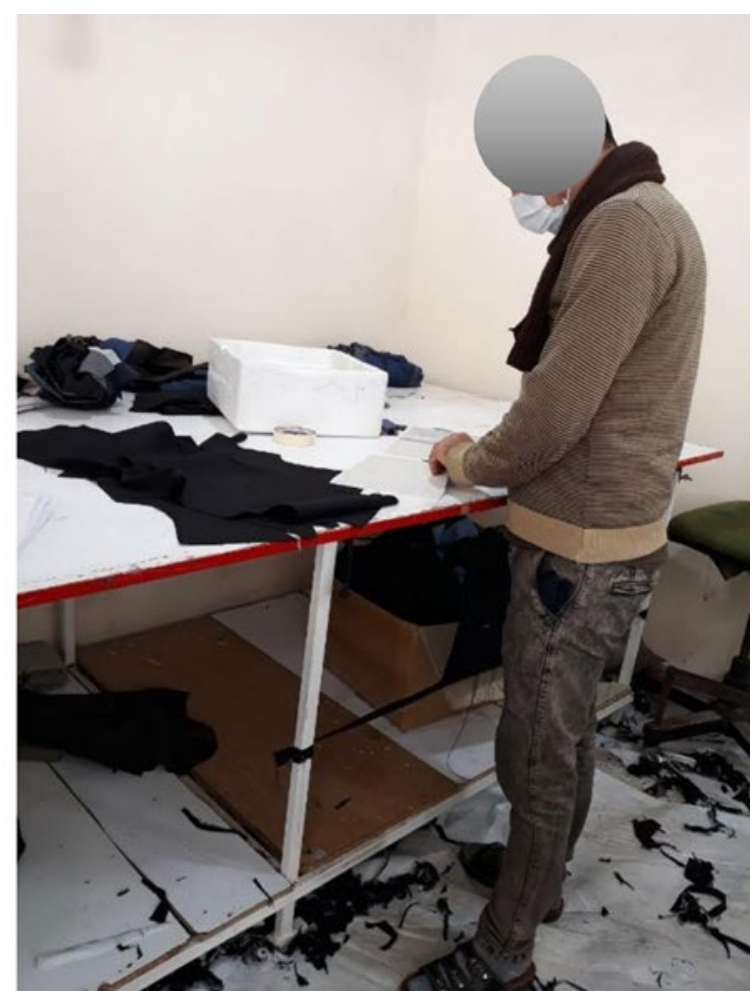

شكل ا. يوسجر كارى ايراتور در وضعيت ايستاده و نشسته

براى بررسى تطابق آنترويومتريك بين افراد و ايستكاههاى

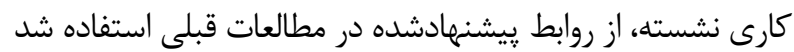

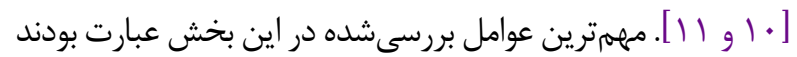
از: ارتفاع صندلى، عمق نشيمنگاه صندلى، عرض نشيمنگًاه صندلى، ارتفاع يشتى صندلى و ارتفاع ميز كار در وضعيت نشسته. مهممترين عامل در طراحى ايستخاههاى كارى ايستاده 》ارتفاع ميز كاره است.

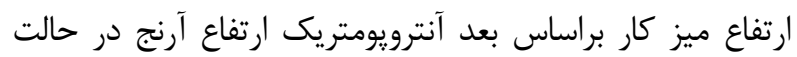

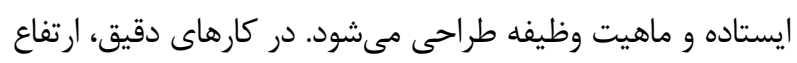

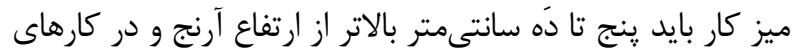

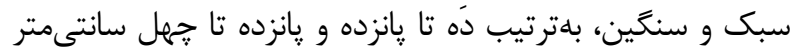

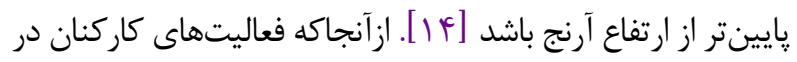
دستة كارهاى سبك قرار مى گرفت، محدودهُ مناسب ارتفاع ميز كار

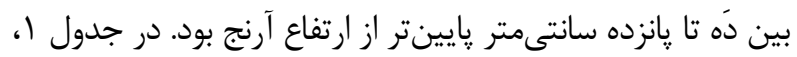

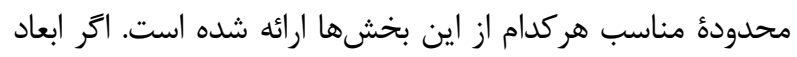

\section{اندازهخيرى ابعاد آنترويومتريك كاركنان}

ابعاد آنترويومتريك افراد در وضعيت هاى بدنى الدئى استاندارد

ISO 7250-1 ايستاده و نشسته براساس ويرايش دوم استاندارد

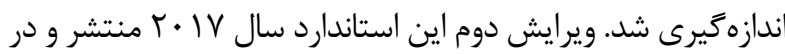

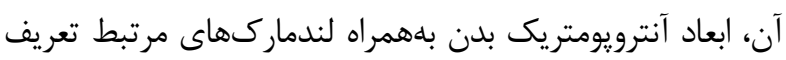

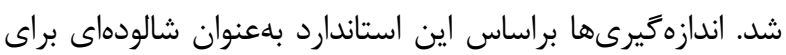

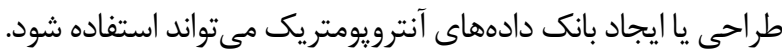
ابعاد اندازهيرىشده در اين مطالعه عبارت بودند از: ارتفاع ركبى، عمق كفلركبى، عمق كفلزانو، ارتفاع آرنج در وضعيت نشسته، يهناى كفل، فضاى رانها، ارتفاع شانه در وضعيت نشسته، ارتفاع

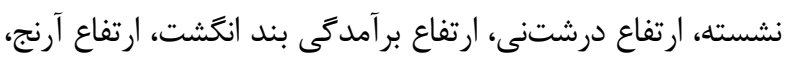
ارتفاع شانه و حد دسترسى در وضعيت ايستاده.

بررسى تطابق آنترويومتريك بين افراد و ايستخاههاى كارى 
به ايستخاهكارى، سطح زيريايى در نظر گرفته شد؛ هرجند در هيجيك از ايستخاههاى كارى زيريايى مشاهده نشائ در نشر.
ايستخاه كارى استفادهده فرد در اين محدوده قرار كيرد، تطابق وجود دارد؛ درغيراينصورت، تطابق وجود ندارد. در اين مطالعه،

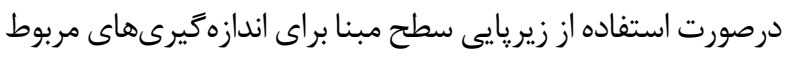

جدول ا. روابط مربوط به تعيين تطابق داشتن يا نداشتن بين ابعاد آنترويومتريك افراد و ابعاد ايستخاهكارى

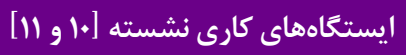

\begin{tabular}{|c|c|}
\hline \multicolumn{2}{|l|}{ ايستكاههاى كارى نشسته [. و 1"] } \\
\hline$(\mathrm{P}+2) \cos (30) \leq \mathrm{SH} \leq(\mathrm{P}+2) \cos (5)$ & محدودهُ تطابق ارتفاع صندلى \\
\hline $1.1 \mathrm{H} \leq \mathrm{SW} \leq 1.3 \mathrm{H}$ & محدودة تطابق عرض نشيمنگًاه صندلى \\
\hline $0.80 \mathrm{~PB} \leq \mathrm{SD} \leq 0.99 \mathrm{~PB}$ & محدوده تطابق عمق نشيمنگًاه صندلى \\
\hline $0.6 S \leq B \leq 0.8 S$ & محدودهُ تطابق ارتفاع يشتى صندلى \\
\hline$E+[(P+2) \cos (30)] \leq$ SiTH $\leq[(P+2) \cos (5)+(0.8517 E)+(0.1483 S)$ & محدوده تطابق ارتفاع ميز كار در حالت \\
\hline
\end{tabular}

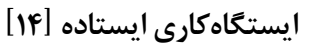

\section{$\mathrm{EH}-15 \leq \mathrm{StTH} \leq \mathrm{EH}-10$}

\section{محدودهُ تطابق ارتفاع ميز كار}

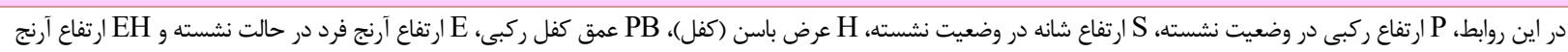

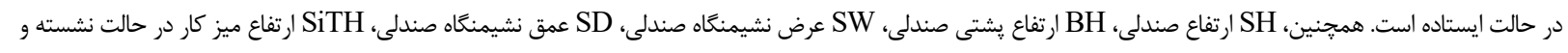
StTH

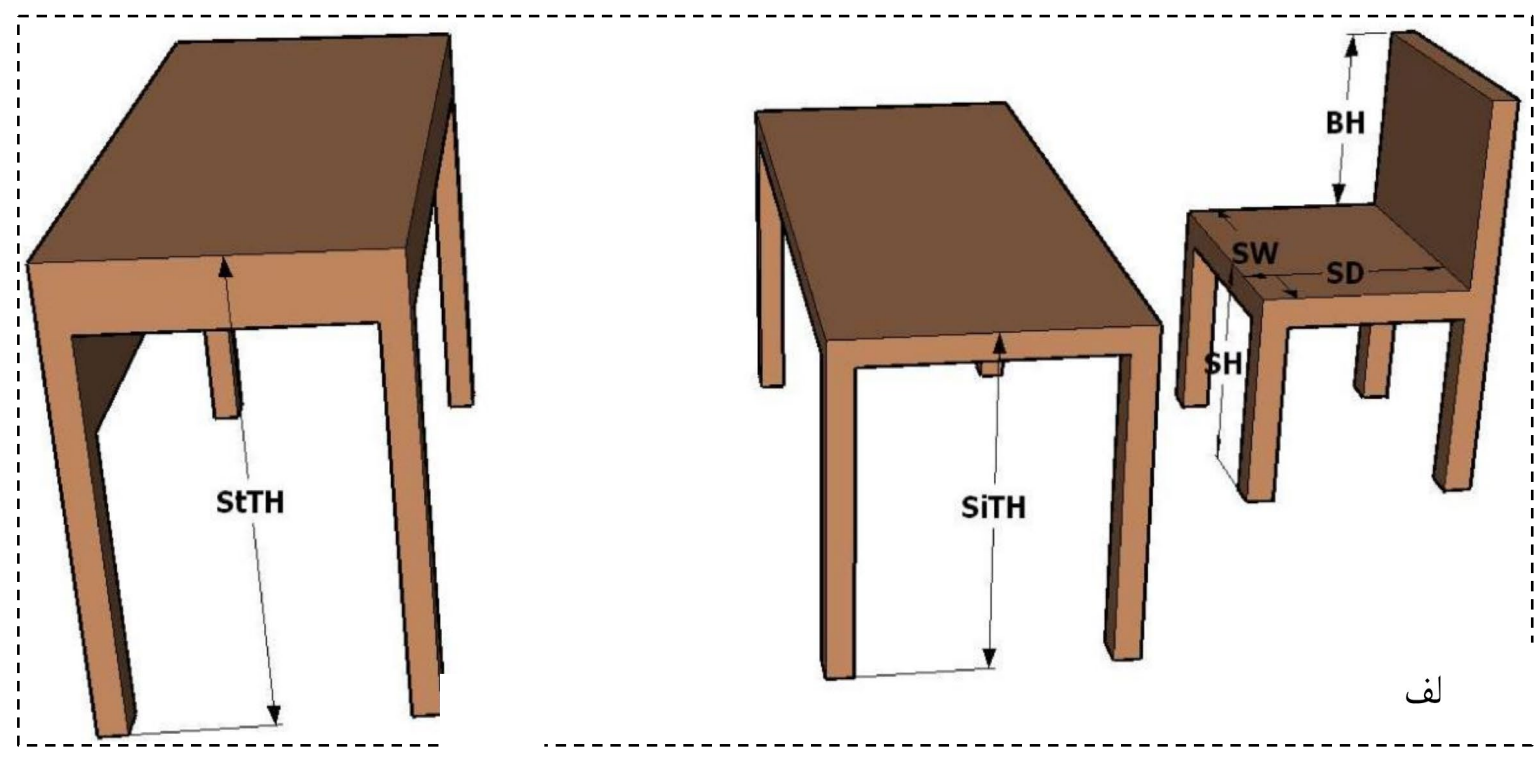

شكل ז. ابعاد آنترويومتريك و ايستَاههاى كار بر رسى شده در مطالعُّ حاضر. الف) ايستًَاهكارى نشسته؛ ب) ايستًَاهكارى ايستاده

بدن، ازجمله گردن و تنه و اندامهاى فوقانى (بازو و ساعد و مج

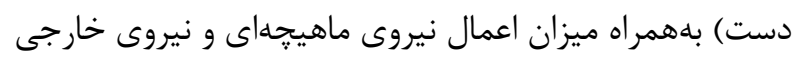

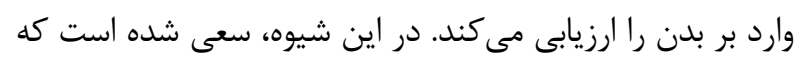
تنظيمات موجود در روش RULA شوند. امتياز نهايى اين روش از يك تا هفت متغير ود دور امتيازهاى

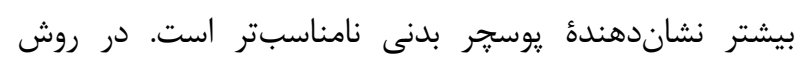

\footnotetext{
${ }^{3}$ Rapid Upper Limb Assessment
}

\begin{abstract}
ارزيابى «وسجر

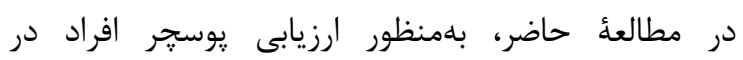

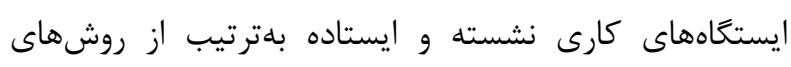
Sanchez-Lite و مERPA ${ }^{1}$ و همكاران [ها [ روش ارزيابى يوسجر NERPA را براساس روش [عULA
\end{abstract}

\footnotetext{
${ }^{1}$ Novel Ergonomic Postural Assessment Method

${ }^{2}$ Rapid Entire Body Assessment
} 


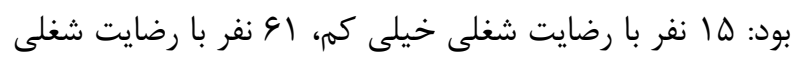

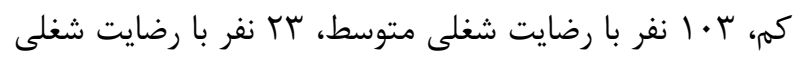

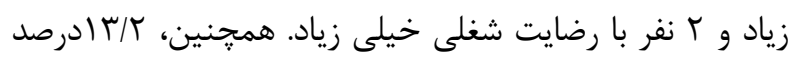

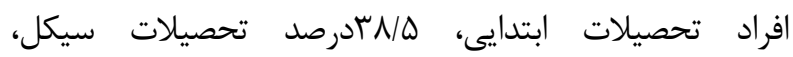

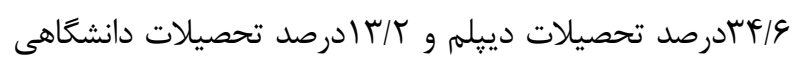

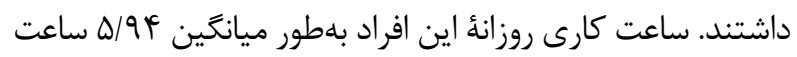

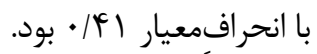

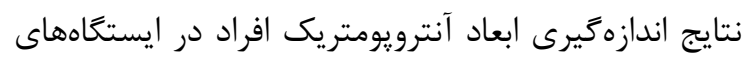

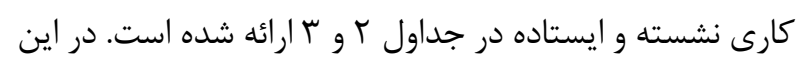

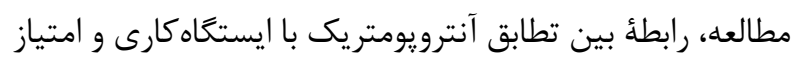

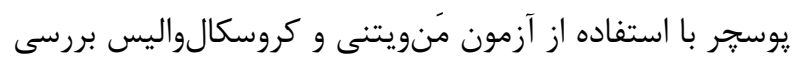

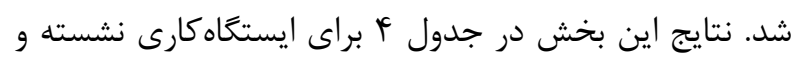

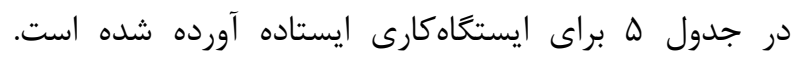

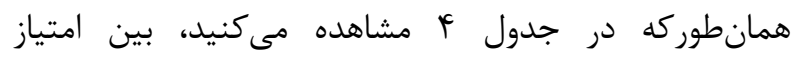

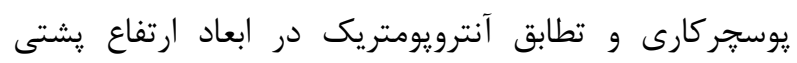

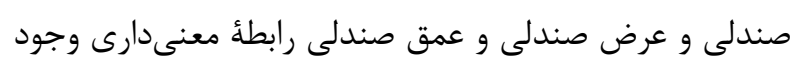

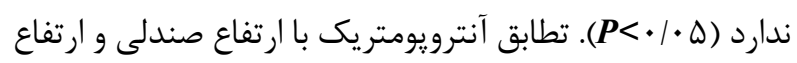

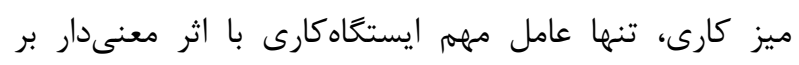

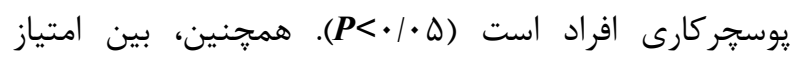

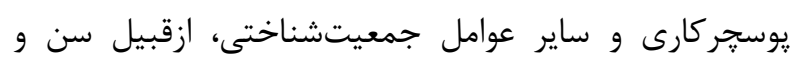

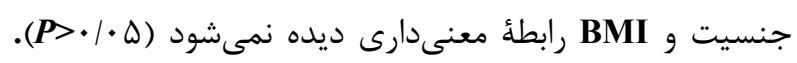

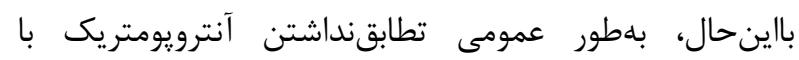

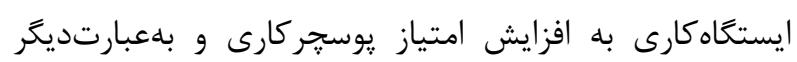

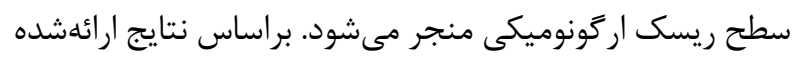

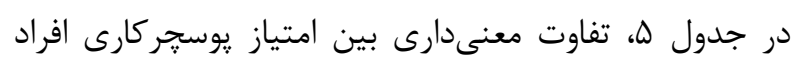

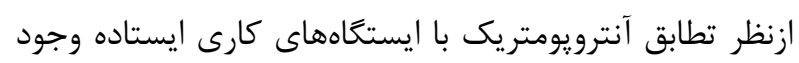

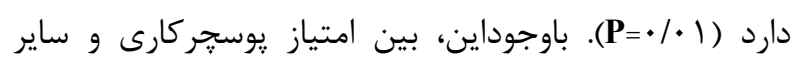

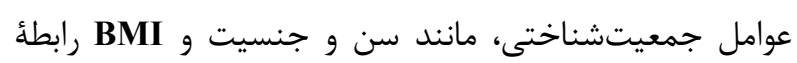

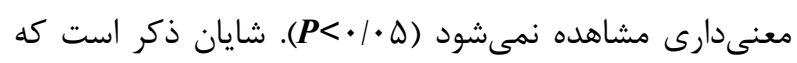

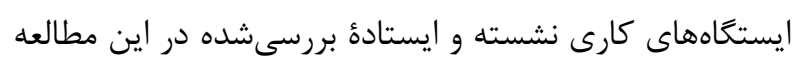
تنظيهم يذير نبودند.
يادشده، امتيازهاى I و r متناظر با سطح اقدام صفر، امتيازهاى

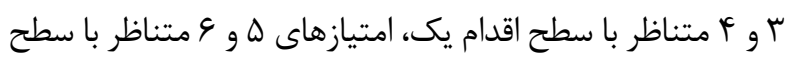

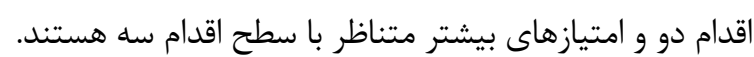

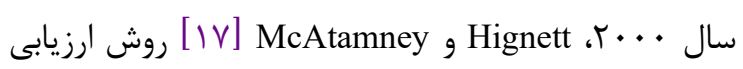

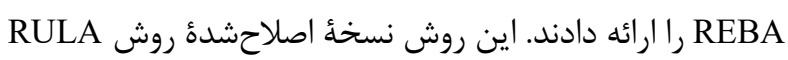

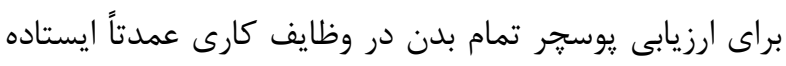

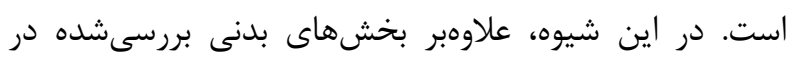

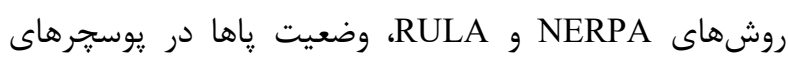

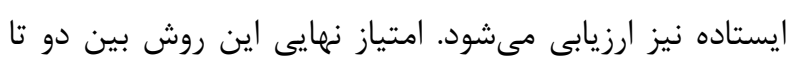

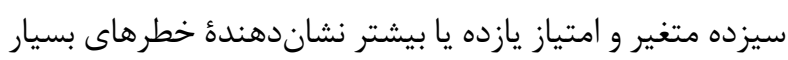

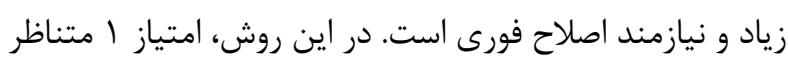

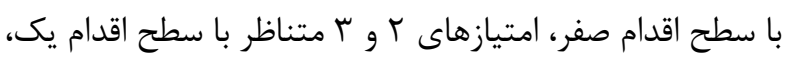

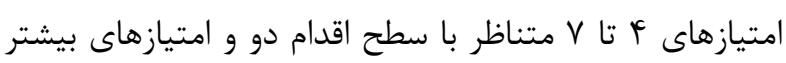
متناظر با سطح اقدام سه هستند. آناليزهاى آمارى

در يزوهش حاضر، براى توصيف دادها ازئ شاخصهاى إماى آمار

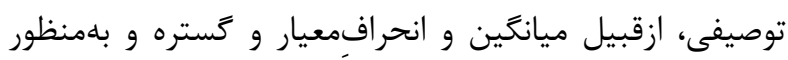

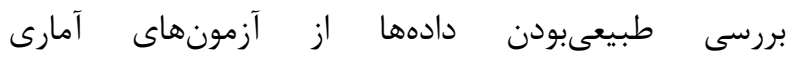

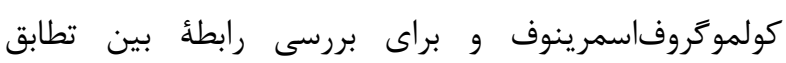

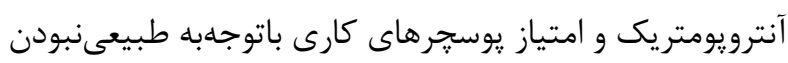
دادهها از آزمون مَنْويتنى استفاده شد ئند

بافته ها

بلهور كلى، در اين مطالعه هـ • ب نفر شركت كردند كه از اين

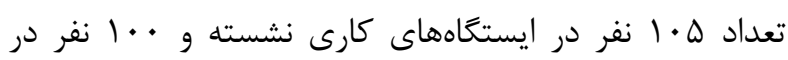

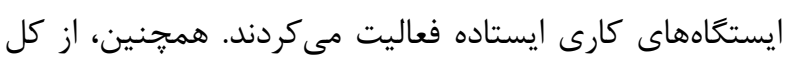

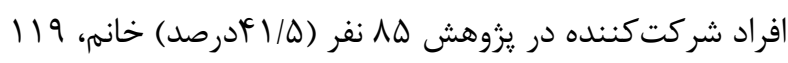

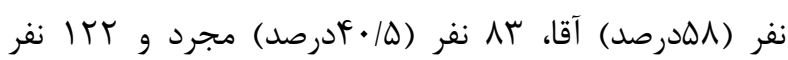

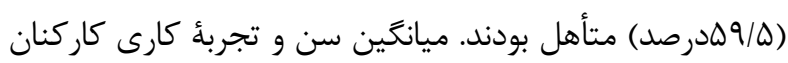

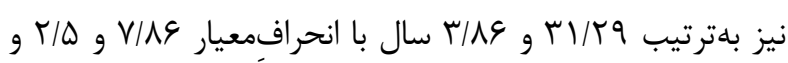

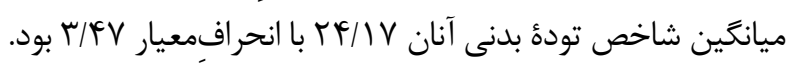
رضايت شغلى در بين كاركنان اين كارخانئ نساجى بدين بانترتين

جدول r. ابعاد آنترويومتريك افراد در ايستكاههاى كارى نشسته (ه.ا نفر )

\begin{tabular}{|c|c|c|c|c|}
\hline صدى هף & صدى ه & انحرافِمعيار & ميانََين & بعد آنترويومتريك \\
\hline $\mathrm{Fq} /$. & $|f| / T)$ & $r / \omega$. & $F F / D \mid$ & ارتفاع ركبى \\
\hline$\Delta r / \cdot 1$ & TG/Tr & G/Td & $F F /$. & عمق كفلر كبى \\
\hline दा/V. & $r \Delta / \cdot \Delta$ & $F / D \mid$ & $\Delta T / \cdot r$ & عمق كفلزانو \\
\hline
\end{tabular}




\begin{tabular}{|c|c|c|c|c|}
\hline صدى هQ & صدك ه & انحر افِمعيار & ميانَين & بعد آنترويومتريك \\
\hline$r N / \cdot \cdot$ & $|V| A \mid$ & $r / \Delta \varphi$ & $r T / K$. & ارتفاع آرنج در وضعيت نشسته \\
\hline FF/TR & $r \Delta / r \Delta$ & $9 / 49$ & rF/VT & يهناى كفل \\
\hline TY/F. & $1 \cdot / \mu$ & r/q & $10 / 0$ & فضاى رانها \\
\hline sF/V. & $\forall \wedge / \cdots$ & VITT & $\Delta \varphi / \Delta \Lambda$ & ارتفاع شانه در وضعيت نشسته \\
\hline$q \mu / \cdot$ & $G T / T$. & $\Lambda / I V$ & $\Lambda Y / \& \Delta$ & ار تفاع نشسته \\
\hline
\end{tabular}

جدول ب. ابعاد آنترويومتريك افراد در ايستخاههاى كارى ايستاده (••( نفر )

\begin{tabular}{|c|c|c|c|c|}
\hline صدى هو & صدى ه & انحرافِمعيار & ميانكين & بعد آنترويومتريك \\
\hline$\Delta 1 / 9 \Delta$ & $r V / \cdots$ & g/VF & $F Y / T V$ & ارتفاع درشتنى \\
\hline$V Y / 9 \Delta$ & $\Delta \varphi / \cdot$ & $N / \cdot r$ & $g F / r \Delta$ & ارتفاع بر آمدكى بند انگشت \\
\hline $\mid r \cdot 1 \cdot$ & $9 \vee / \cdot \Delta$ & $\mid r / \cdots$ & $1 \cdot V / \cdot \Delta$ & ارتفاع آرنج \\
\hline $1 \% / 90$ & $|K N| \cdot \Delta$ & $\mid f / \wedge \&$ & $\mid f \cdot 1 \cdot$ & 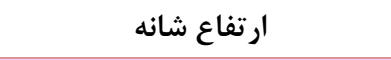 \\
\hline$\Lambda \cdot / \cdot$ & qr/.. & N/DT & $\checkmark 1 / 99$ & حد دسترسى در وضعيت ايستاده \\
\hline
\end{tabular}

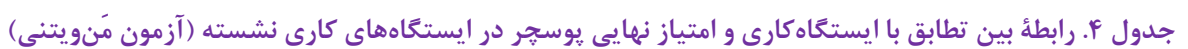

\begin{tabular}{|c|c|c|c|c|}
\hline مقدار P P & 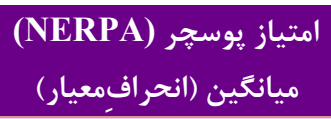 & تعداد (درصد) & وضعيت تطابق & بعد ايستكاهكارى \\
\hline \multirow{2}{*}{.199} & F/VD $( \pm \cdot / 91)$ & 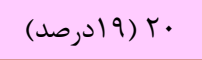 & ت تطابق داشتن & \multirow{2}{*}{ ندازهُ هِتتى صندلى } \\
\hline & $f / 9 q( \pm 1 / \cdot \wedge)$ & له (I (درصد) & تطابقنداشتن & \\
\hline \multirow{2}{*}{$.1 \cdot 1$} & $R / T V( \pm I / T H)$ & rr (Q/ • זدرصد) & تطابقداشتن & \multirow{2}{*}{ ارتفاع صندلى } \\
\hline & F/AF $( \pm \cdot / 9 T)$ & r V/ (q/هدرصد) & تطابقنداشتن & \\
\hline \multirow{2}{*}{$\cdot \mid \Delta V$} & $f / \Delta \wedge( \pm 1 / / \Lambda)$ & | & ت تطابق داشتن & \multirow{2}{*}{ عرض صندلى } \\
\hline & F/VA $( \pm \cdot / 9 \Delta)$ & F & تطابقنداشتن & \\
\hline \multirow{2}{*}{. } & f/gf $( \pm 1 / \cdot 1)$ & $($ ) V V V & ت تطابق داشتن & \multirow{2}{*}{ عمق صندلى } \\
\hline & $F / \wedge \Delta( \pm|/| f)$ & 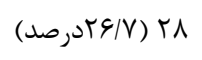 & ت تطابقنداشتن & \\
\hline \multirow{2}{*}{$\cdot / \cdot \Delta$} & $F / T r( \pm 1 / T \cdot)$ & V IV (I ادرصد) & ت تطابقداشتن & \multirow{2}{*}{ ارتفاع ميز كار } \\
\hline & f/Vq ( $\pm \cdot / 99)$ & ( $)$ M & ت تطابقنداشتن & \\
\hline \multirow{2}{*}{$\cdot \mid 19$} & $F / 9 \wedge( \pm \cdot / 9 V)$ & ا & 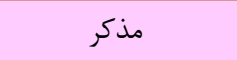 & \multirow{2}{*}{ جنسيت } \\
\hline & $F / V T( \pm|/| F)$ & (I & مؤنث & \\
\hline \multirow{4}{*}{$\cdot / V$} & $\Delta / / \varphi( \pm \cdot / V \Delta)$ & (هرصد/Vد 9 & كموزن & \multirow{4}{*}{ BMI } \\
\hline & $f / 9 q( \pm 1 / \cdot \wedge)$ & ( & وزن طبيعى & \\
\hline & F/VT ( $\pm \cdot / 9 V)$ & عץ (ז/ז سدرصد) & اضافهوزن & \\
\hline & $F / Q \cdot( \pm I / T r)$ & fi | (T/r/درصد) & جاق & \\
\hline \multirow{4}{*}{$\cdot / \mu$} & F/r & 9 & كو جكتر از • · سال & \multirow{4}{*}{ سن } \\
\hline & $F / \Lambda F( \pm 1 / \cdot 9)$ & ( & 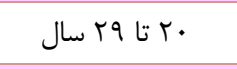 & \\
\hline & $4 / 99( \pm \cdot / 91)$ & سז (ז// זدرصد) & 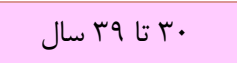 & \\
\hline & $F / \Delta V( \pm I / \cdot V)$ & 191 (1/1/درصد) & بزركتر از • ck سال & \\
\hline
\end{tabular}


جدول ه. رابطة بين تطابق با ايستخَاهكارى و امتياز نهايى يوسجر در ايستخَاههاى كارى ايستاده (آزمون مَنويتنى)

\begin{tabular}{|c|c|c|c|c|}
\hline مقدار p & امتياز بوسجر (انحرافِمعيار) & تعداد (درصد) & وضعيت تطابق & بعد ايستخاه كارى \\
\hline \multirow{2}{*}{.$/ \cdot 1$} & $f / r q( \pm 1 / 94)$ & 19 (9 (ادرصد) & تطابقداشتن & \multirow{2}{*}{ ارتفاع ميز كار } \\
\hline & $\Delta / \mathcal{F F}^{\mathcal{F}}( \pm \backslash / \wedge \Delta)$ & 1 1 (1 1درصد) & تطابقنداشتن & \\
\hline \multirow{2}{*}{$\cdot / \Delta V$} & $\Delta / T r( \pm \mid / \& r)$ & ه ه ( هدرصد) & مذكر & \multirow{2}{*}{ جنسيت } \\
\hline & $\Delta / / r( \pm r / / r)$ & أfl (ألر,صد) & مؤنث & \\
\hline \multirow{4}{*}{.199} & $\Delta / \Gamma( \pm T / T \Delta)$ & 9 (عدرصد) & كموزن & \multirow{4}{*}{ BMI } \\
\hline & $\Delta / T \Delta( \pm 1 / ৭ \hookrightarrow)$ & $(ص, د) \& V$ & وزن طبيعى & \\
\hline & $\Delta / T r( \pm I / \Lambda \vee)$ & F F ( F ادرصد) & اضافهوزن & \\
\hline & $\Delta / \mid \Delta( \pm \mid / \mu \Psi)$ & سا (ז/درصد) & جاق & \\
\hline \multirow{4}{*}{$\cdot / \mathrm{\wedge} \wedge$} & $\Delta / r r( \pm r / I V)$ & 9 (9 (صرصد) & كوجكتر از •· سال & \multirow{4}{*}{ سن } \\
\hline & $\Delta / I V( \pm T / / \Lambda)$ & أl(أluرصد) & • r تا qr سال & \\
\hline & $\Delta / \mathcal{A} \Delta( \pm \mid / \Delta \&)$ & اس (اسادرصد) & 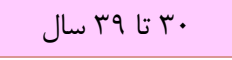 & \\
\hline & $\Delta / \cdots( \pm \mid / \Psi \vee)$ & 1919 (ادرصد) & بزركتر از • r سال & \\
\hline
\end{tabular}

ايستخاههاى كارى ايستاده سه مورد به اصلاح و مداخله فورى

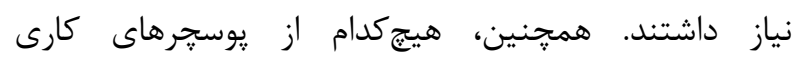

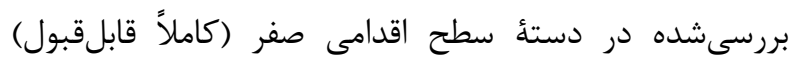
نيستند.
نتايج حاصل از ارزيابى يوسجر افراد در ايستخاههاى كارى

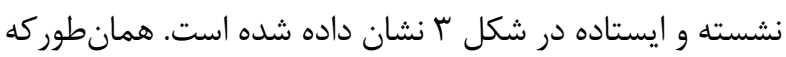
مشاهده مى كنيد، در اين ايستخاههاى كارى نشسته هيج كدام از يوسجرهاى كارى به اصلاح فورى نياز نداشتند؛ ولى در نـ
ايستخاهكارى نشسته (نتايج NERPA)

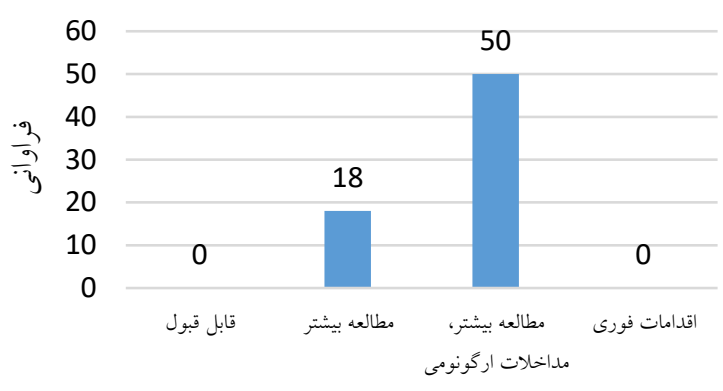

ايستخاه كارى ايستاده (نتايجREBA)

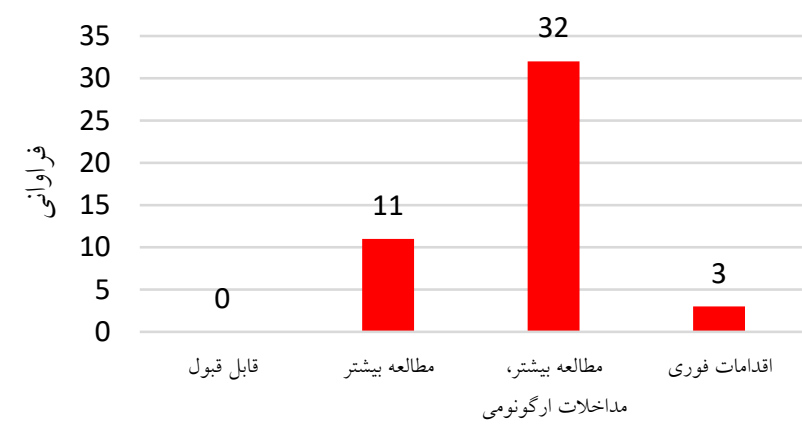

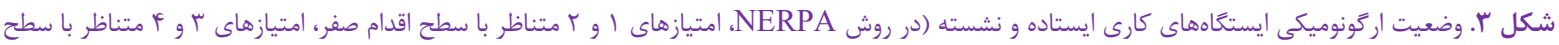

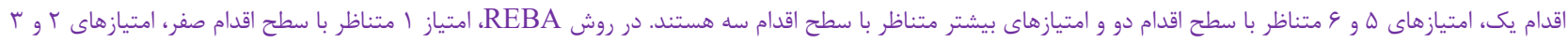

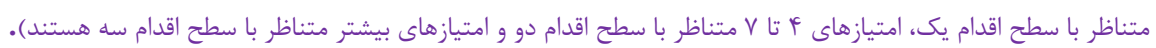

بحث

ايستخاههاى كارى نشسته، تطابق آنترويومتريك با ارتفاع صندلى و ميز كارى رابطهُ معنىدارى با امتياز يوسجر كارى داشت. همجنين در

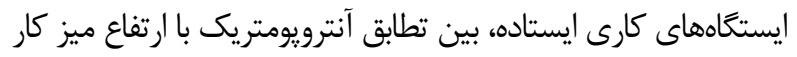

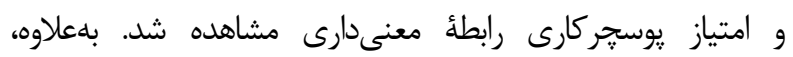

در تحقيق حاضر، يوسجرهاى كارى افراد در يكى از صنايع بافندگى بررسى شد. در ارزيابى ايستخاههاى كارى نشسته، روش ئرى

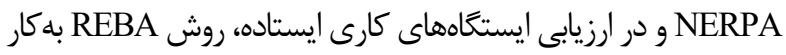

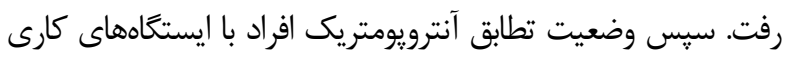

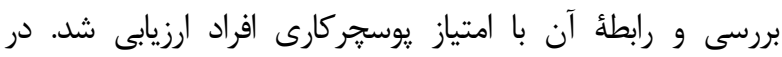


صندلىهايى با ارتفاع زياد نيز به خهمشن كردن و تنه براى تسلط بر كار منجر مىشود. با افزايش ارتفاع صندلى، فضاى عمودى مونى موردنياز

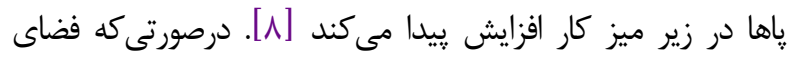

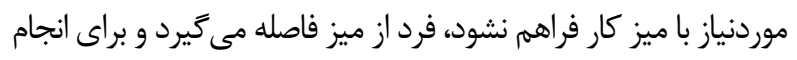

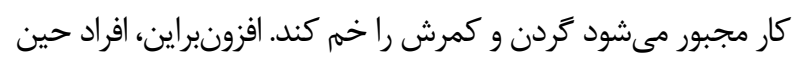

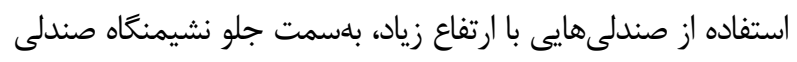

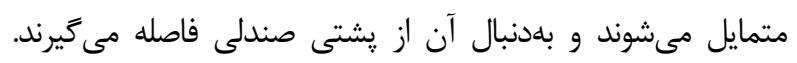

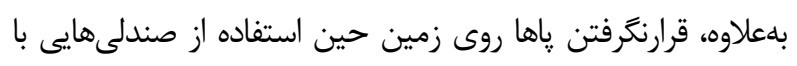

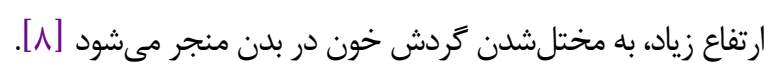

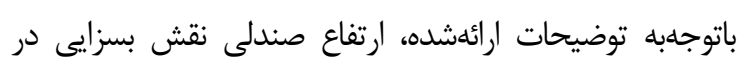

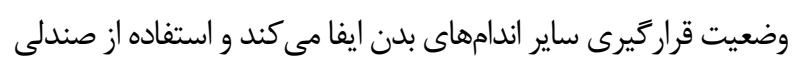

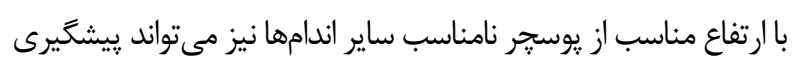
كند. در اين مطالعه، مشاهده شد كه در تمامى موارد تطابقنداشتن

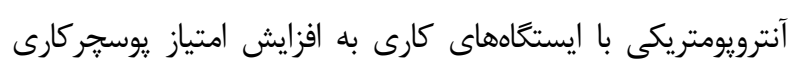

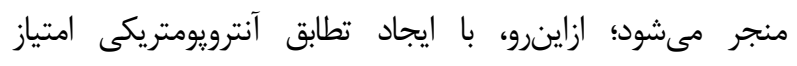

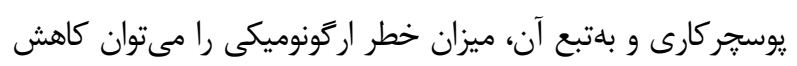

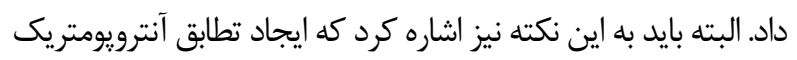
بين افراد و ايستكاههاى كارى بلتننهايى نمىتواند تضمين كنندة

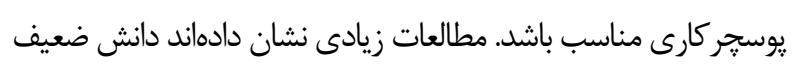

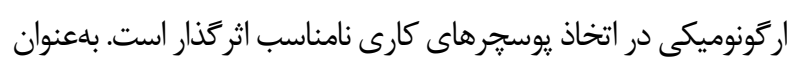

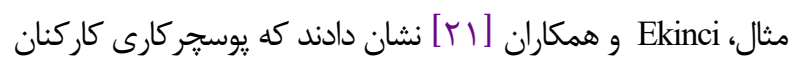

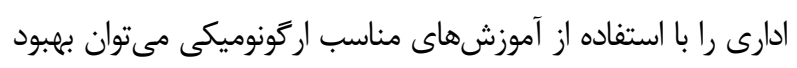

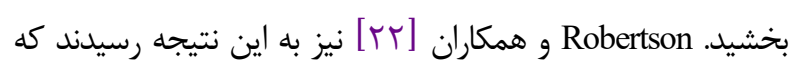

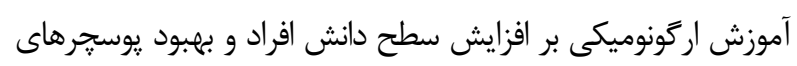

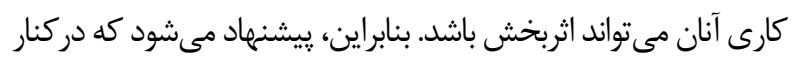
طراحى مناسب ايستكاههاى كارى و فراهمسازى تطابق آنترويومتريك،

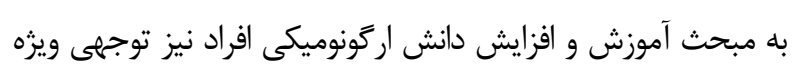
شود. - ان اين مطالعه نيز همانند هر يروهش ديكرى محدوديتهايى دارد

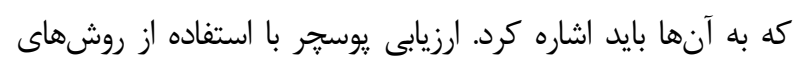

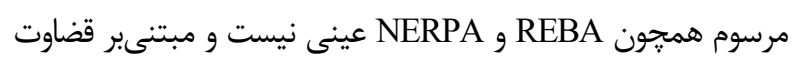

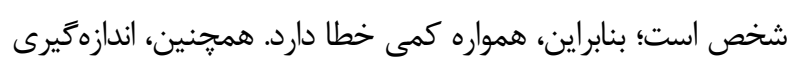

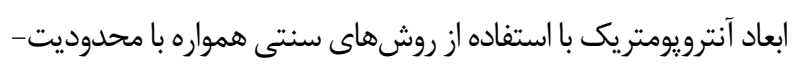

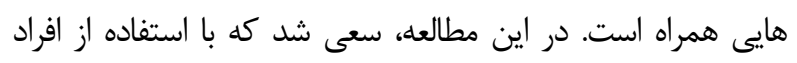

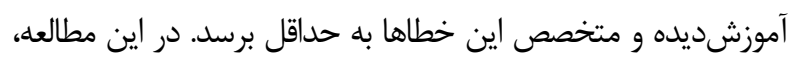

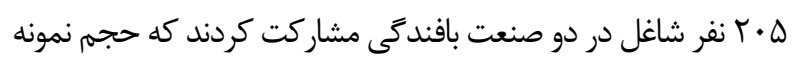

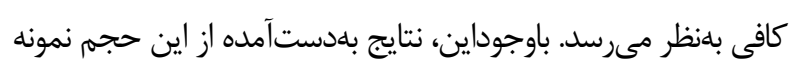

تطابقنداشتن آنترويومتريك با ايستكاههاى كارى در تمامى ابعاد به

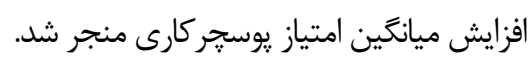

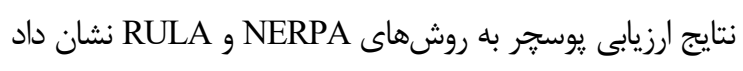

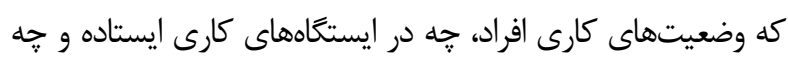

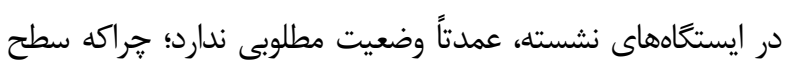

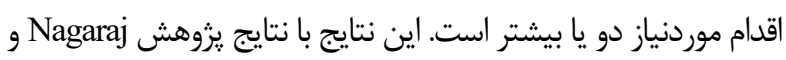

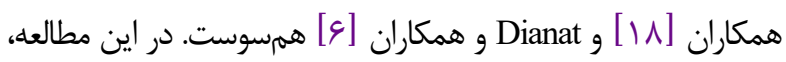

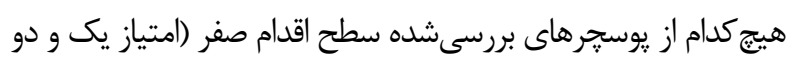

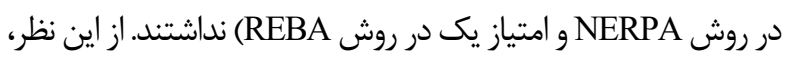

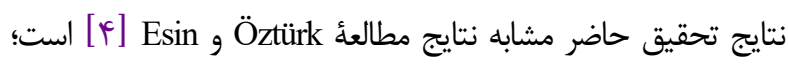

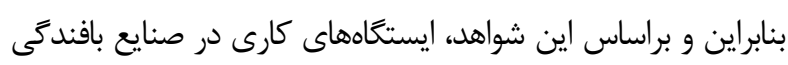

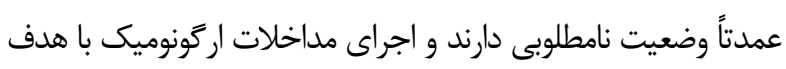

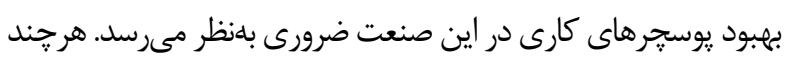

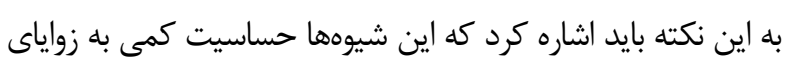
بدن دارند و برخى مواقع تغيير حشمخير در وضعيت بدنى به به تغيير إنها

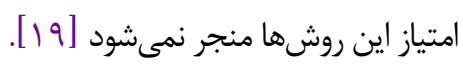
افزونبراين، نتايج تحقيق حاضر حاكى از آن بود كه بين تطابق آنقايق

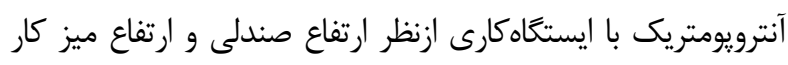

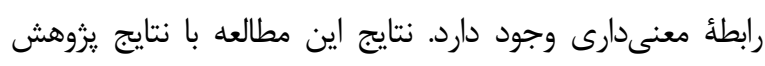
Tondre

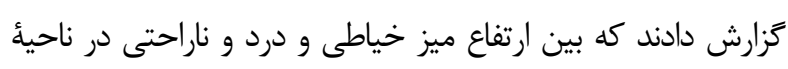

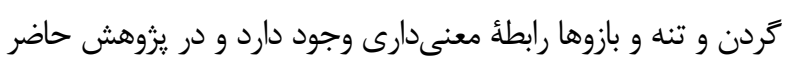

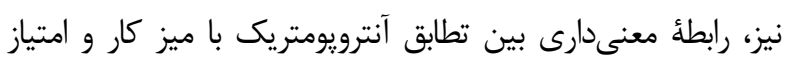

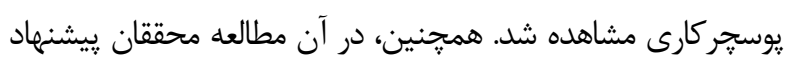

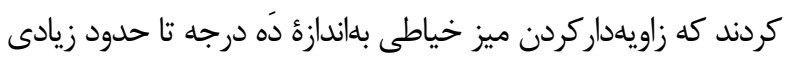

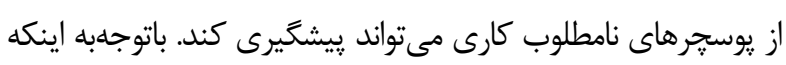

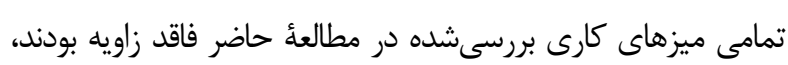
امكان مقايسٔ نتايج دو مطالعه از اين نظر وجود ندارئ ندارد. همانطوركه قبلاً نيز اشاره كرديم، بين تطابق آنترويومتريك با بال

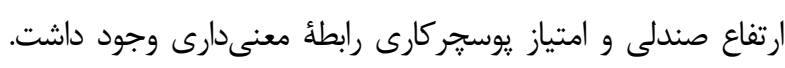

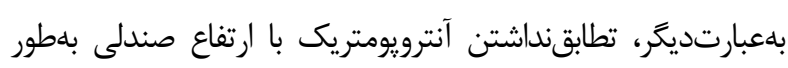

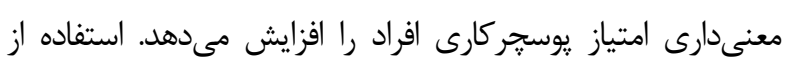

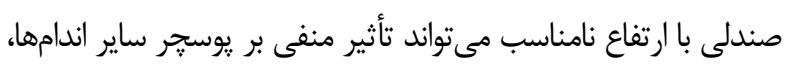

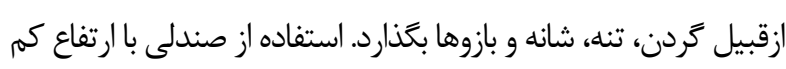

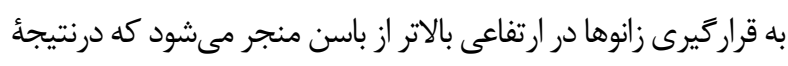

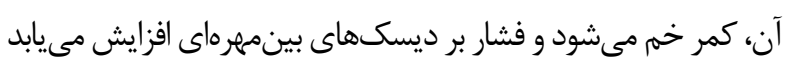

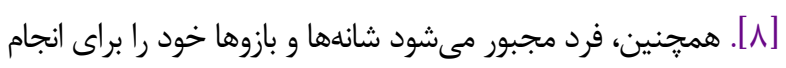
كار بالا بكشد كه در درازمدت ممكن است آسيبزا باشد. استفاده از 


$$
\text { تأييديه اخلاقى }
$$

اين مطالعه در كميتهٔ اخلاق در يزوهش دانشگاه علوم يزشكى همدان بررسى و تأييد شده است (كد اخلاق: (IR.UMSHA.REC.1398.969). ناخفته نماند مشاركت در اين لرنى مطالعه كاملاً اختيارى بود و تمامى افراد قبل از ورود به مطالعه، فرم رضايتنامئ آثاهانه را مطالعه و امضا كردند.

$$
\text { تعارض منافع }
$$$$
\text { ميان نويسند }
$$

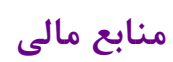

منابع مالى يزوهش حاضر را دانشعاه علوم يزشكى همدان تأمين

$$
\text { كرده است. }
$$

\section{References}

1. Sultan-taïeb H, Parent-lamarche A, Gaillard A, Stock $\mathrm{S}$, Nicolakakis N, Hong QN, et al. Economic evaluations of ergonomic interventions preventing work-related musculoskeletal disorders : a systematic review of organizational-level interventions. BMC Public Health. 2017;17(1):1-13. [DOI:10.1186/s12889-017-4935-y] [PMID] [PMCID]

2. Genaidy AM, Rinder MM, Sequeira R, A-Rehim AD. The Work Compatibility Improvement Framework: Theory and application of improvement action and intervention strategies. Ergonomics. 2009;52(5):52459. [DOI:10.1080/00140130802395638] [PMID]

3. Akodu A, Tella B, Adebisi O. Prevalence, Pattern and Impact of Musculoskeletal Disorders among Sewing Machine Operators in Surulere Local Government Area of Lagos State, Nigeria. Indian J Physiother Occup Ther (An Int J). 2013;7(2):15-20. [DOI:10.5958/j.0973-5674.7.2.004]

4. Öztürk N, Esin MN. Investigation of musculoskeletal symptoms and ergonomic risk factors among female sewing machine operators in Turkey. Int J Ind Ergon. 2011;41(6):585-91.

[DOI:10.1016/j.ergon.2011.07.001]

5. Schibye B, Skov T, Ekner D, Christiansen MLTJU, Sjgaard G. Musculoskeletal symptoms among sewing machine operators. Scand J Work Environ Health. 1995;21(6):427-34. [DOI:10.5271/sjweh.58] [PMID] تعميممدادنى به كل افراد نيست و هر گونه تعميم اين نتايج بايد با احتياط

$$
\text { نتيجه كَيرى }
$$

يوسجر كارى در صنعت بافندگى عمدتاً نامطلوب و نيازمند مداخلات ارگونوميك است. بهطوركلى، تطابقنداشتن آنترويومتريك بين فرد و ايستعاه كارى به افزايش امتياز يوسجر كارى و افزايش مواجهه با خطر عوامل ارگونومى منجر مىشود. بالينحال، تطابق آنترويومتريك با ارتفاع صندلى و ارتفاع

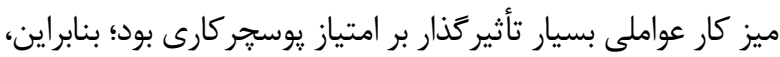

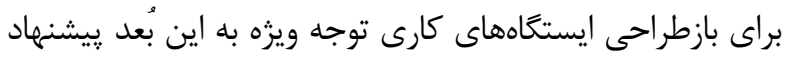
مىشود.

$$
\begin{aligned}
& \text { تقدير و تشكر } \\
& \text { نويسندگان مقاله از معاونت محترم تحقيقات و فناورى } \\
& \text { دانشعاه علوم يزشكى همدان بهخاطر حمايتهاى مالى تشكر }
\end{aligned}
$$

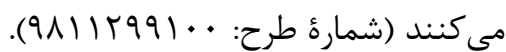

6. Dianat I, Kord M, Yahyazade P, Karimi MA, Stedmon AW. Association of individual and work-related risk factors with musculoskeletal symptoms among Iranian sewing machine operators. Appl Ergon. 2015;51:18088. [DOI:10.1016/j.apergo.2015.04.017] [PMID]

7. Delleman NJ, Berndsen MB. Touch-typing VDU operation: Workstation adjustment, working posture and workers' perceptions. Int $\mathrm{J}$ Ind Ergon. 2002;45(7):514-35. [DOI:10.1080/00140130210140319] [PMID]

8. Pheasant S, Haslegrave CM. Bodyspace: Anthropometry, ergonomics and the design of work. Boca Raton: CRC Press; 2018. [DOI:10.1201/9781315375212]

9. Moghadam RH, Shabani M, Lotfi Y, Ghasemi F, Mohammadi Y. Study of Hand Anthropometry Dimensions on Middle-Aged Women and Men in Hamadan. J Ergon. 2018;6(2):46-54. [DOI:10.30699/jergon.6.2.46]

10. Parcells C, Stommel M, Hubbard R. Mismatch of Classroom Furniture and Student Body Dimensions Empirical Findings and Health Implications. J Adolesc Health. 1999;24(4):265-73. [DOI:10.1016/S1054139X(98)00113-X]

11. Abd Rahman NI, Md Dawal SZ, Yusoff N, Mohd Kamil NS. Anthropometric measurements among four Asian countries in designing sitting and standing 
workstations. Sadhana (Acad Proc Eng Sci). 2018;43(1):1-9. [DOI:10.1007/s12046-017-0768-8]

12. Dianat I, Karimi MA, Asl Hashemi A, Bahrampour S. Classroom furniture and anthropometric characteristics of Iranian high school students: Proposed dimensions based on anthropometric data. Appl Ergon. 2013;44(1):101-8.

[DOI:10.1016/j.apergo.2012.05.004] [PMID]

13. Parvez MS, Parvin F, Shahriar MM, Kibria G. Design of Ergonomically Fit Classroom Furniture for Primary Schools of Bangladesh. J Eng. 2018;2018(4):1-9. [DOI: $10.1155 / 2018 / 3543610$ ]

14. Stack T, Ostrom LT, Wilhelmsen CA. Occupational Ergonomics: A Practival Approach. New Jeresy: John Wiley \& Sons; 2016. [DOI:10.1002/9781118814239]

15. Sanchez-Lite A, Garcia M, Domingo R, Sebastian MA. Novel Ergonomic Postural Assessment Method (NERPA) Using Product-Process Computer Aided Engineering for Ergonomic Workplace Design. PLoS One. 2013;8(8):e72703. [DOI:10.1371/journal.pone.0072703] [PMID] [PMCID]

16. Corlett EN, McAtamney L. RULA: a survey method for the investigation of world-related upper limb disorders. Appl Ergon. 1993;24(2):91-9. [DOI:10.1016/0003-6870(93)90080-S]

17. Hignett S, McAtamney L. Rapid Entire Body Assessment (REBA). Appl Ergon. 2000;31(2):201-5. [DOI:10.1016/S0003-6870(99)00039-3]

18. Sakthi Nagaraj T, Jeyapaul R, Mathiyazhagan K. Evaluation of ergonomic working conditions among standing sewing machine operators in Sri Lanka. Int J Ind Ergon. 2019;70:70-83. [DOI:10.1016/j.ergon.2019.01.006]

19. Ghasemi F, Mahdavi N. A new scoring system for the Rapid Entire Body Assessment (REBA) based on fuzzy sets and Bayesian networks. Int J Ind Ergon. 2020;80:103058. [DOI:10.1016/j.ergon.2020.103058]

20. Tondre S, Deshmukh T. Guidelines to sewing machine workstation design for improving working posture of sewing operator. Int $\mathrm{J}$ Ind Ergon. 2019;71:37-46. [DOI:10.1016/j.ergon.2019.02.002]

21. Ekinci Y, Atasavun Uysal S, Kabak VY, Duger T. Does ergonomics training have an effect on body posture during computer usage? J Back Musculoskelet Rehabil. 2019;32(1): 1-5. [DOI:10.3233/BMR181196] [PMID]

22. Robertson M, Amick BC, DeRango K, Rooney T, Bazzani L, Harrist R, et al. The effects of an office ergonomics training and chair intervention on worker knowledge, behavior and musculoskeletal risk. Appl Ergon. 2009;40(1):124-35. [DOI:10.1016/j.apergo.2007.12.009] [PMID] 